\title{
Trinuclear and Hexanuclear Lanthanide(III) Complexes of the Chiral 3+3 Macrocycle: X-ray Crystal Structures and Magnetic Properties
}

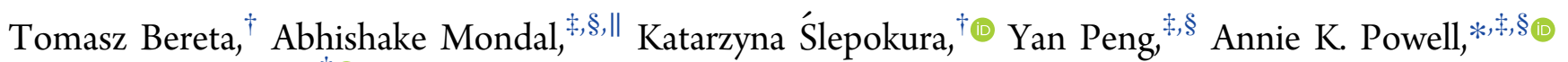 \\ and Jerzy Lisowski* ${ }^{\dagger}+0$
}

\author{
${ }^{\dagger}$ Department of Chemistry, University of Wrocław, 14 F. Joliot-Curie, 50-383 Wrocław, Poland \\ ${ }^{\ddagger}$ Institute of Inorganic Chemistry, Karlsruhe Institute of Technology (KIT), Engesserstrasse 15, 76131 Karlsruhe, Germany \\ ${ }^{\S}$ Institute of Nanotechnology, Karlsruhe Institute of Technology (KIT), Hermann-von-Helmholtz-Platz 1, 76344 \\ Eggenstein-Leopoldshafen, Germany
}

Supporting Information

\begin{abstract}
A new triphenolic hexaaza chiral macrocyclic amine $\mathrm{L}$ forms trinuclear complexes $\mathbf{1 - 3}$ with rare earth metal lanthanide(III) ions ( $\mathrm{Ln}=\mathrm{Dy}, \mathrm{Eu}$, and Y) with the general formula $\left[\mathrm{Ln}_{3} \mathrm{~L}\left(\mu_{3}-\mathrm{OH}\right)_{2}\left(\mathrm{NO}_{3}\right)_{4}\left(\mathrm{H}_{2} \mathrm{O}\right)_{2}\right] \cdot x \mathrm{CH}_{3} \mathrm{OH}$. The crystal structures of the nitrate derivatives of this type reveal the presence of a $\left\{\mathrm{Ln}_{3}\left(\mu_{3}-\mathrm{OH}\right)_{2}\right\}$ core within the macrocycle. For the chloride derivative of dysprosium(III) 4, a duplex of the trinuclear compound is formed to give the hexanuclear $\left[\mathrm{Dy}_{6} \mathrm{~L}_{2}\left(\mu_{3}-\mathrm{OH}\right)_{3}\left(\mu_{3}-\mathrm{O}\right)\left(\mu_{2}-\mathrm{Cl}\right)_{3} \mathrm{Cl}_{4}\left(\mathrm{H}_{2} \mathrm{O}\right)_{2}\right]$ compound, in which two trinuclear macrocyclic units are linked by bridging chloride anions, supplemented by a hydrogen bond connecting the central oxo and hydroxo bridges as well as by weak interactions at the periphery of the macrocycle. The nuclear magnetic resonance spectra of these complexes reveal a dynamic behavior in solution related to exchange of axial ligands and hindered rotation of phenyl substituents. Magnetic studies of the nitrate (1-3) and chloride (4) dysprosium(III) complexes suggest the presence of weak ferromagnetic interactions between neighboring metal centers. The interaction is strongest for compound $\mathbf{1}$, and for the related duplex compound 4, it appears to be somewhat weaker. The ac susceptibility measurements for complexes $\mathbf{1}$ and $\mathbf{4}$ confirm their field-induced single-molecule magnet behavior with the following characteristics: $U_{\text {eff }}=10.6 \mathrm{~cm}^{-1}(15.2 \mathrm{~K}), \tau_{0}=2.05 \times 10^{-4} \mathrm{~s}$ under 2500 Oe dc fields for $1 ; U_{\text {eff }}=7.9 \mathrm{~cm}^{-1}(11.4 \mathrm{~K}), \tau_{0}=1.68 \times$ $10^{-4} \mathrm{~s}$ under a 3000 Oe dc field for 4.
\end{abstract}

\section{INTRODUCTION}

Large macrocyclic ligands constitute a versatile platform for the formation of multinuclear metal complexes, the binding of lanthanide(III) ions, or the formation of metal complexes with interesting magnetic properties. ${ }^{1}$ In particular, large macrocycles derived from diamines and aromatic dialdehydes can form complexes with transition metal ions, ${ }^{2-4}$ lanthanide ions, $^{5-8}$ or mixed $\mathrm{d}-\mathrm{f}$ complexes. ${ }^{9}$ Some time ago we demonstrated that such ligands can also be used for the formation of trinuclear lanthanide complexes. ${ }^{5}$ Thus, the macrocyclic amine $L^{\prime}$ derived from $3+3$ condensation of enantiopure trans-1,2-diaminocyclohexane and 2,6-diformyl-4methylphenol (Scheme 1) binds a lanthanide hydroxo cluster $\mathrm{Ln}_{3}\left(\mu_{3}-\mathrm{OH}\right)_{2}$ in its center (Scheme 1$)$. This ligand also exhibits other binding modes toward lanthanide(III) ions and can form also mono- ${ }^{7,8}$ and dinuclear ${ }^{5}$ lanthanide(III) complexes. Importantly, ligands such as $\mathrm{L}^{\prime}$ allow for the combination of the chiral environment, formation of a polynuclear lanthanide(III) cluster, and the increased stability of lanthanide complexes due to the macrocyclic effect. It should be mentioned that polynuclear chiral complexes are candidates for materials exhibiting magneto-chiral effects. ${ }^{10}$ It is also worth mentioning that some polynuclear lanthanide(III) complexes based on the $\operatorname{Ln}_{3}\left(\mu_{3}-\mathrm{OH}\right)_{2}$ core behave as singlemolecule magnets $(\mathrm{SMMs})^{11}$ and that similar trinuclear hydroxo-bridged structural motifs can also be found in $\mathrm{d}-\mathrm{f}$ magnetic materials. ${ }^{12}$ In particular, the $o$-vanillin complex containing a $\left\{\mathrm{Dy}_{3}\left(\mu_{3}-\mathrm{OH}\right)_{2}\right\}$ core was the first molecule to be identified as having a toroidal and essentially nonmagnetic ground state, crossing to single-molecule magnet with an applied field or an increased temperature. The essentially nonmagnetic ground state and toroidal magnetic moment are associated with the chiral, propeller-like arrangements of the individual dysprosium(III) magnetic moments. ${ }^{11}$ Furthermore, recently it was shown that using $3 \mathrm{~d}$ connectors is a useful strategy for enhancing toroidal moments. ${ }^{12 e, f}$

As has been shown by Tang et al., the trinuclear dysprosium complexes of the ligand $\mathrm{L}^{\prime}$ containing the $\left\{\mathrm{Dy}_{3}\left(\mu_{3}-\mathrm{OH}\right)_{2}\right\}$ unit exhibit SMM behavior under an applied static magnetic field ${ }^{6}$ and the mononuclear dysprosium(III) complexes of this macrocycle also show field-induced single-ion magnet behavior. $^{8}$

Received: November 22, 2018

Published: March 12, 2019 
Scheme 1. Trinuclear Lanthanide Complexes of Macrocycles $L^{\prime}$ and $L$ and Synthesis of the Macrocyclic Ligands ${ }^{a}$<smiles>CC(C)(C)c1cc(C=O)c(O)c(C=O)c1</smiles><smiles>COC(C)[C@H](C)C(C)(C)C(C)(C)C</smiles>

$\mathrm{H}_{3} \mathrm{~L}^{\prime \prime}$
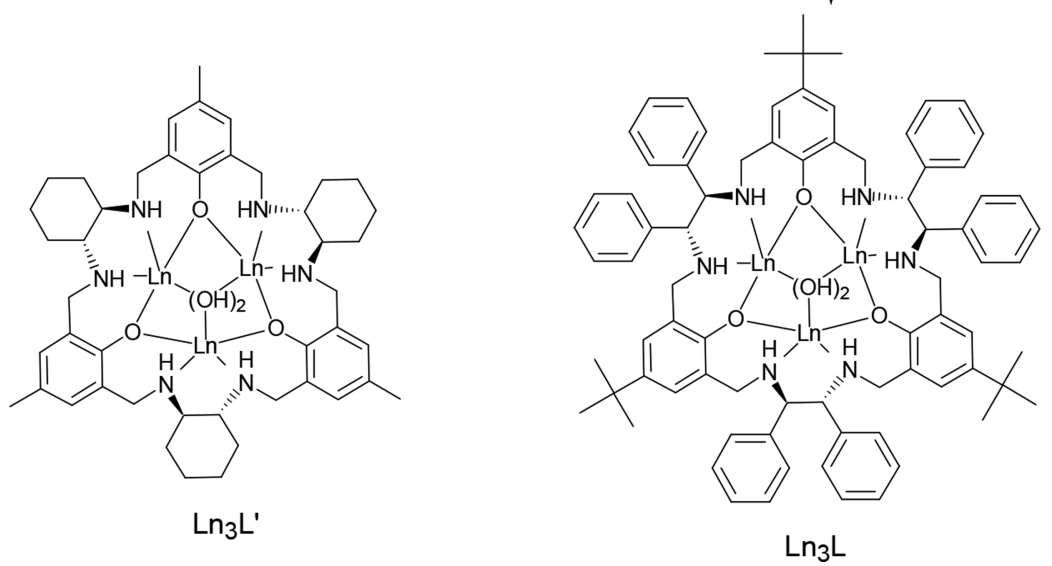

${ }^{a}$ Axial ligands and charges of complexes omitted for the sake of simplicity.

Here we present the synthesis of a new $3+3$ chiral macrocycle $L$ (Scheme 1) based on a different diamine, the enantiopure $(1 R, 2 R)$-1,2-diphenylethylenediamine, and discuss the magnetic properties of its trinuclear dysprosium(III) complexes. We also present the crystal structures and solution characterization of the analogous europium(III) and yttrium(III) derivatives. In addition, we show that the chloride derivative of the dysprosium(III) complex of $\mathrm{L}$ is a hexanuclear ${ }^{13}$ complex, in which the dysprosium(III) ions belonging to two different trinuclear macrocyclic units are connected by additional chloride bridges.

\section{RESULTS AND DISCUSSION}

Synthesis. The macrocycle L (see Scheme 1) can be easily obtained in a good yield in a fashion similar to that used for the analogue with methyl rather than the current tert-butyl substituent. $^{2 \mathrm{e}}$ The synthesis is based on a selective $3+3$ condensation of enantiopure $(1 R, 2 R)$-1,2-diphenylethylenediamine with 2,6-diformyl-4-tert-butylphenol followed by sodium borohydride reduction of the formed macrocyclic imine $\mathrm{H}_{3} \mathrm{~L}^{\prime \prime}$ into amine $\mathrm{H}_{3} \mathrm{~L}$ (Figures $\mathrm{S} 1$ and $\mathrm{S} 2$ ). Macrocycle $\mathrm{H}_{3} \mathrm{~L}$ readily reacts with europium(III) or dysprosium(III) salts in solution as confirmed by the presence of paramagnetically shifted lines in the nuclear magnetic resonance (NMR) spectra of crude mixtures. Without added base, we were not able to isolate pure well-defined products from such solutions. On the other hand, the addition of a base such as sodium hydroxide, potassium hydroxide, or trimethylamine resulted in the formation of crystalline products containing lanthanide(III) hydroxo clusters.

Crystal Structures. The molecular structures of the isomorphic $\left[\mathrm{Ln}_{3} \mathrm{~L}\left(\mu_{3}-\mathrm{OH}\right)_{2}\left(\mathrm{NO}_{3}\right)_{4}\left(\mathrm{H}_{2} \mathrm{O}\right)_{2}\right] \cdot x \mathrm{CH}_{3} \mathrm{OH}$ nitrate 
Table 1. Crystallographic Data of the Compounds ${ }^{a}$

\begin{tabular}{|c|c|c|c|c|}
\hline & $\begin{array}{c}1\left[\mathrm{Dy}_{3} \mathrm{~L}\left(\mu_{3^{-}}\right.\right. \\
\left.\mathrm{OH})_{2}\left(\mathrm{NO}_{3}\right)_{4}\left(\mathrm{H}_{2} \mathrm{O}\right)_{2}\right] \\
5.8 \mathrm{MeOH}\end{array}$ & $\begin{array}{c}2\left[\mathrm{Eu}_{3} \mathrm{~L}\left(\mu_{3^{-}}\right.\right. \\
\left.\mathrm{OH})_{2}\left(\mathrm{NO}_{3}\right)_{4}\left(\mathrm{H}_{2} \mathrm{O}\right)_{2}\right] \\
5.4 \mathrm{MeOH}\end{array}$ & $\begin{array}{c}3\left[\mathrm{Y}_{3} \mathrm{~L}\left(\mu_{3^{-}}\right.\right. \\
\left.\mathrm{OH})_{2}\left(\mathrm{NO}_{3}\right)_{4}\left(\mathrm{H}_{2} \mathrm{O}\right)_{2}\right] \\
6.3 \mathrm{MeOH}\end{array}$ & $\begin{array}{c}4\left[\mathrm{Dy}_{6} \mathrm{~L}_{2}\left(\mu_{3}-\mathrm{OH}\right)_{3}\left(\mu_{3}-\mathrm{O}\right)\left(\mu_{2}-\right.\right. \\
\left.\mathrm{Cl})_{3} \mathrm{Cl}_{4}\left(\mathrm{H}_{2} \mathrm{O}\right)_{2}\right] \cdot 3 \mathrm{MeOH} \cdot 8 \mathrm{H}_{2} \mathrm{O}\end{array}$ \\
\hline CCDC No. & 1501188 & 1501189 & 1501190 & 1501191 \\
\hline chemical formula & $\mathrm{C}_{83.8} \mathrm{H}_{116.2} \mathrm{Dy}_{3} \mathrm{~N}_{10} \mathrm{O}_{24.8}$ & $\mathrm{C}_{83.4} \mathrm{H}_{114.6} \mathrm{Eu}_{3} \mathrm{~N}_{10} \mathrm{O}_{24.4}$ & $\mathrm{C}_{84.3} \mathrm{H}_{118.2} \mathrm{~N}_{10} \mathrm{O}_{25.3} \mathrm{Y}_{3}$ & $\mathrm{C}_{159} \mathrm{H}_{209} \mathrm{Cl}_{7} \mathrm{Dy}_{6} \mathrm{~N}_{12} \mathrm{O}_{23}$ \\
\hline$M_{\mathrm{r}}$ & 2147.96 & 2103.52 & 1943.21 & 3879.52 \\
\hline crystal system, space group & monoclinic, $P 2_{1}$ & monoclinic, $P 2_{1}$ & monoclinic, $P 2_{1}$ & tetragonal, $P 4_{1} 2_{1} 2$ \\
\hline temperature $(\mathrm{K})$ & $100(2)$ & $100(2)$ & $130(2)$ & $100(2)$ \\
\hline$a, b, c(\AA)$ & $\begin{array}{l}11.607(6), 28.647(7) \\
14.940(5)\end{array}$ & $\begin{array}{l}11.623(3), 28.722(4) \\
14.915(5)\end{array}$ & $\begin{array}{l}11.747(3), 28.541(5) \\
14.939(3)\end{array}$ & $20.057(3), 20.057(3), 41.817(9)$ \\
\hline$\alpha, \beta, \gamma(\mathrm{deg})$ & $90,108.77(3), 90$ & $90,108.85(3), 90$ & $90,109.36(3), 90$ & $90,90,90$ \\
\hline$V\left(\AA^{3}\right)$ & $4703(3)$ & $4712(2)$ & $4725.4(19)$ & $16822(6)$ \\
\hline$Z$ & 2 & 2 & 2 & 4 \\
\hline radiation type & Mo $\mathrm{K} \alpha$ & Mo K $\alpha$ & Mo $\mathrm{K} \alpha$ & Mo $\mathrm{K} \alpha$ \\
\hline$\mu\left(\mathrm{mm}^{-1}\right)$ & 2.43 & 2.05 & 1.90 & 2.81 \\
\hline crystal size $(\mathrm{mm})$ & $0.23 \times 0.18 \times 0.13$ & $0.38 \times 0.23 \times 0.08$ & $0.43 \times 0.26 \times 0.17$ & $0.20 \times 0.11 \times 0.10$ \\
\hline diffractometer & $\begin{array}{l}\text { Agilent Technologies, } \\
\text { Xcalibur }\end{array}$ & Kuma KM4-CCD & Kuma KM4-CCD & Agilent Technologies, Xcalibur \\
\hline absorption correction & analytical & analytical & multiscan & analytical \\
\hline$T_{\min }, T_{\max }$ & $0.680,0.787$ & $0.564,0.867$ & $0.845,1.000$ & $0.653,0.756$ \\
\hline $\begin{array}{l}\text { no. of measured, independent, and } \\
\text { observed }[I>2 \sigma(I)] \text { reflections }\end{array}$ & $20837,15570,12105$ & $32995,17021,11876$ & $33538,17367,9696$ & $31328,18354,14111$ \\
\hline$R_{\text {int }}$ & 0.033 & 0.068 & 0.072 & 0.049 \\
\hline$(\sin \theta / \lambda)_{\max }\left(\AA^{-1}\right)$ & 0.617 & 0.617 & 0.617 & 0.664 \\
\hline$R\left[F^{2}>2 \sigma\left(F^{2}\right)\right], w R\left(F^{2}\right), S$ & $0.058,0.131,1.05$ & $0.072,0.198,1.04$ & $0.058,0.126,1.00$ & $0.051,0.097,1.01$ \\
\hline no. of reflections & 15570 & 17021 & 17367 & 18354 \\
\hline no. of parameters & 1088 & 1117 & 1113 & 964 \\
\hline no. of restraints & 143 & 847 & 100 & 16 \\
\hline$\Delta \rho_{\max }, \Delta \rho_{\min }\left(\mathrm{e} \AA^{-3}\right)$ & $1.70,-1.67$ & $1.93,-1.64$ & $0.64,-0.69$ & $0.80,-0.90$ \\
\hline absolute structure parameter & $0.002(8)$ & $0.115(11)$ & $-0.005(5)$ & $-0.021(8)$ \\
\hline
\end{tabular}

derivatives $[\mathrm{Ln}=$ dysprosium(III) (1), $x=5.8$; europium(III) (2), $x=5.4$; or yttrium(III) (3), $x=6.3]$ crystallize in space group $P 2_{1}$, and the chloride derivative $\left[\mathrm{Dy}_{6} \mathrm{~L}_{2}\left(\mu_{3}-\mathrm{OH}\right)_{3}\left(\mu_{3}\right.\right.$ O) $\left.\left(\mu_{2}-\mathrm{Cl}\right)_{3} \mathrm{Cl}_{4}\left(\mathrm{H}_{2} \mathrm{O}\right)_{2}\right] \cdot 3 \mathrm{CH}_{3} \mathrm{OH} \cdot 8 \mathrm{H}_{2} \mathrm{O}$ (4) crystallizes in space group $\mathrm{P}_{1} \mathrm{2}_{1} 2$ (Table 1 ; selected bond lengths, angles, and $\mathrm{Ln}-\mathrm{Ln}$ distances are listed in Table S1). Compounds 1-3 are isomorphic; thus, only compound $\mathbf{1}$ will be discussed in detail. The structure of $\mathbf{1}$ shows an extended macrocycle $L$ with a helical conformation (Figure 1). The macrocycle adopts a relatively flat conformation with approximate $D_{3}$ symmetry. The helical twist of the macrocycle is obvious from the propeller arrangement of the three pyridine fragments. The macrocycle $L$ in this trinuclear complex binds each lanthanide(III) ion by two nitrogen atoms belonging to the same 1,2diphenylethylenediamine unit and by two phenolate oxygen atoms, which act as a bridge between two lanthanide(III) ions.

All three lanthanide(III) ions are additionally bridged by two $\mu_{3}$-hydroxo anions positioned above and below the plane of the three $\mathrm{Ln}$ ions, forming an $\left\{\mathrm{Ln}_{3}\left(\mu_{3}-\mathrm{OH}\right)_{2}\right\}$ core. The coordination spheres of the lanthanide(III) ions are completed by axial ligands, and the sets of these ligands are not equivalent. One of the lanthanide(III) ions in trinuclear complexes $\mathbf{1 - 3}$ is coordinated by two monodendate nitrate anions, while the remaining two lanthanide(III) ions are coordinated by one nitrate anion and water molecule. As a result of this axial ligation, the whole complex is of approximate $C_{2}$ symmetry as was also found for the $\mathrm{Dy}_{3}$ triangle of Tang et al. Some of the methanol solvent molecules, tert-butyl groups, phenyl groups, and nitrate anions in the structure of the yttrium(III) complex are disordered; additional disorder related to metal ion positions is observed for the dysprosium(III) and europium(III) derivatives (see Experimental Section for details).

The coordination geometries around the metal centers were analyzed for compound 1 using SHAPE. ${ }^{14}$ The continuous shape measurements (CShM's) are listed in Table S2, and those with the smallest deviations from the idealized coordination geometries are listed in Table 2. Compound $\mathbf{1}$ is highly disordered both for the ligands and for the dysprosium(III) positions; thus, the coordination polyhedra of the dysprosium(III) ions were analyzed using the atoms with the largest occupation. As shown in Figure 2 and Table 2, the eight-coordinate environments around the dysprosium(III) ions in compound $\mathbf{1}$ are distorted from the ideal shapes. The deviation values of Dy1 and Dy3 from the idealized square antiprism (SAPR) geometry are 0.912 and 1.246 , respectively, and the deviation value of Dy2 from the triangular dodecahedron (TDD) shape is 1.065 .

The structure of the chloride derivative $\left[\mathrm{Dy}_{6} \mathrm{~L}_{2}\left(\mu_{3}-\mathrm{OH}\right)_{3}\left(\mu_{3}\right.\right.$ O) $\left.\left(\mu_{2}-\mathrm{Cl}\right)_{3} \mathrm{Cl}_{4}\left(\mathrm{H}_{2} \mathrm{O}\right)_{2}\right] \cdot 3 \mathrm{CH}_{3} \mathrm{OH} \cdot 8 \mathrm{H}_{2} \mathrm{O}$ (4) indicates a connection between two macrocyclic trinuclear dysprosium(III) units via chloride bridges (Figure 3). Each of these units contains a trinuclear dysprosium(III) hydroxo cluster. The two $\left\{\mathrm{Dy}_{3}\right\}$ planes of the two macrocyclic units in 4 are almost parallel to each other [the angle between them is equal to $\left.0.57(2)^{\circ}\right]$ with a distance between the centers of the two $\left\{\mathrm{Dy}_{3}\right\}$ triangles equal to $5.3670(6) \AA$. The distance between the central bridging oxygen atoms belonging to the two different units is equal to $2.95(2) \AA$, which is not consistent with the presence of two $\mu_{3}-\mathrm{OH}$ hydroxo groups oriented in such a way that $\mathrm{O}-\mathrm{H}$ bonds point to the center of the 

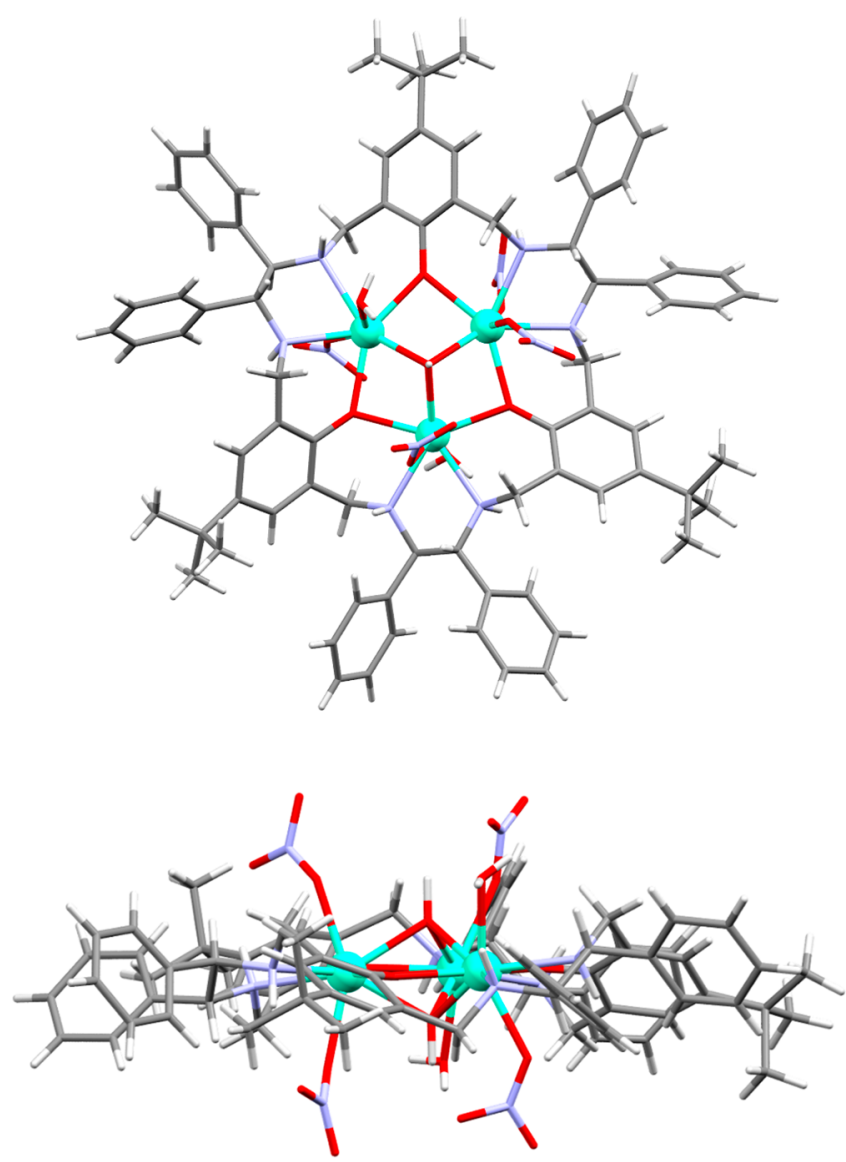

Figure 1. Top and side views of the $\left[\mathrm{Dy}_{3} \mathrm{~L}\left(\mu_{3}-\mathrm{OH}\right)_{2}\left(\mathrm{NO}_{3}\right)_{4}\left(\mathrm{H}_{2} \mathrm{O}\right)_{2}\right]$ complex in compound 1 [axial ligands and disorder omitted, dysprosium(III) ions indicated as turquoise spheres].

molecule. Instead, this distance indicates the presence of an $\mathrm{O}-\mathrm{H} \cdots \mathrm{O}$ hydrogen bonding situation. This is in accord with the presence of seven chloride anions in the structure; the charge balance requires that both trinuclear units cannot contain $\left\{\mathrm{Dy}_{3}\left(\mu_{3}-\mathrm{OH}\right)_{2}\right\}$ cores at the same time, and one of the bridges has to be a $\mu_{3}$-oxo bridge. Thus, one macrocycle contains a $\left\{\mathrm{Dy}_{3}\left(\mu_{3}-\mathrm{OH}\right)_{2}\right\}$ core, and the other contains a $\left\{\mathrm{Dy}_{3}\left(\mu_{3}-\mathrm{OH}\right)\left(\mu_{3}-\mathrm{O}\right)\right\}$ core. These two variants cannot be distinguished in the crystal structure. In addition to the hydrogen bonding, the two trinuclear macrocyclic units are also connected by bridging ligands; three chloride anions are sandwiched between two macrocycles and bridge three pairs of dysprosium(III) ions belonging to different macrocycles. Each dysprosium(III) ion is bound to the macrocycle by two nitrogen atoms and two bridging phenolate oxygen atoms in the same manner as in the nitrate derivative discussed above. The coordination spheres of the six dysprosium(III) ions are
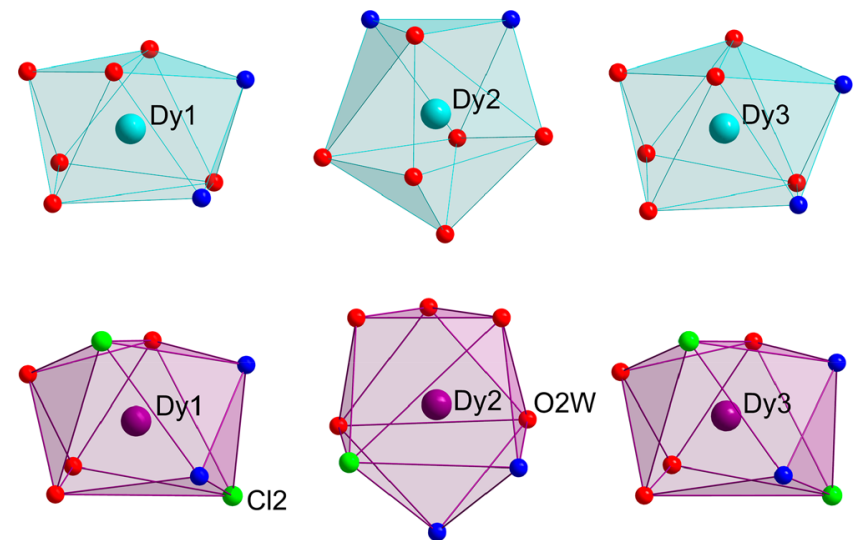

Figure 2. Coordination polyhedra of dysprosium(III) ions in compounds 1 (top) and 4 (bottom).

completed by the outer axial ligands resulting in a $\mathrm{N}_{2} \mathrm{Cl}_{2} \mathrm{O}_{4}$ donor set for each dysprosium(III) ion, except one disordered position with a $\mathrm{N}_{2} \mathrm{ClO}_{5}$ donor set. One metal ion of each trinuclear unit is coordinated by an outer chloride anion, while the positions of the outer ligands of the remaining two dysprosium(III) ions are disordered and are occupied by the coordinated water molecules and chloride anions (with a site occupancy of $\sim 0.5$ each).

The geometries around the eight-coordinated dysprosium(III) ions are irregular (Figure 2 and Table 2). In compound 4, the coordination spheres of Dy1 and Dy3 ions also adopt deformed square antiprism geometries, and the chemical environment around Dy2 can be described as a triangular dodecahedron (regardless of the ligand, i.e., $\mathrm{Cl}^{-}$ion or $\mathrm{H}_{2} \mathrm{O}$ molecule, present in the disordered coordination sphere). The SHAPE analysis for dysprosium(III) ions in compound 4 indicates greater distortion compared with that of compound 1, which is confirmed by the deviation values from the corresponding idealized coordination geometries regardless of whether the ligand is a chloride or $\mathrm{H}_{2} \mathrm{O}$ molecule (see Table 2 and Table S2)

The trinuclear macrocyclic units in $\mathbf{4}$ are of approximate $C_{3}$ symmetry ignoring the disordered axial ligands. The conformation of the macrocycle is not affected much by dimer formation and is similar to that observed for the nitrate derivative.

The structure of this chloride derivative corresponding to the dimer of the trinuclear dysprosium(III) complex of $\mathrm{L}$ is very different from that of the chloride derivative of the yttrium(III) complex of $\mathrm{L}^{\prime}, 5$ where the trinuclear macrocyclic units $\left[\mathrm{Y}_{3} \mathrm{~L}^{\prime} \mathrm{Cl}_{3}\left(\mu_{3}-\mathrm{OH}\right)_{2}(\mathrm{MeOH})\left(\mathrm{H}_{2} \mathrm{O}\right)_{2}\right]^{+}$are not organized into chloride-bridged dimers. This difference is unlikely to result from the different coordination preferences of the

Table 2. Continuous Shape Measurements (CShM's) for Dy ${ }^{\mathrm{III}}$ Ions in $\mathrm{ML}_{8}$ Fragments in Compounds 1 and $4^{a}$

\begin{tabular}{|c|c|c|c|c|c|c|c|c|}
\hline \multirow[b]{2}{*}{ ideal reference polyhedron ${ }^{b}$} & \multicolumn{3}{|c|}{ compound 1} & \multicolumn{5}{|c|}{ compound 4} \\
\hline & Dy1 & Dy2 & Dy3 & $\mathrm{Dy}^{c}$ & $\mathrm{Dy}^{d}$ & $\mathrm{Dy} 2^{c}$ & $\mathrm{Dy} 2^{d}$ & Dy3 \\
\hline BTPR $(C 2 v)$ & 1.730 & 2.000 & 1.425 & 2.288 & 1.935 & 2.234 & 1.618 & 2.225 \\
\hline TDD $(D 2 d)$ & 1.789 & 1.065 & 1.511 & 2.095 & 1.955 & 1.759 & 1.538 & 1.945 \\
\hline SAPR $(D 4 d)$ & 0.912 & 2.032 & 1.246 & 1.648 & 1.599 & 1.875 & 1.829 & 1.554 \\
\hline
\end{tabular}

${ }^{a}$ Only those with the smallest deviations from the idealized coordination geometries are given. For the full analysis, see Table S2. ${ }^{b}$ Abbreviations: BTPR, biaugmented trigonal prism; TDD, triangular dodecahedron; SAPR, square antiprism. ${ }^{c} \mathrm{Cl}^{-}$as a ligand in the disordered coordination sphere ${ }^{d} \mathrm{H}_{2} \mathrm{O}$ as a ligand in the disordered coordination sphere 

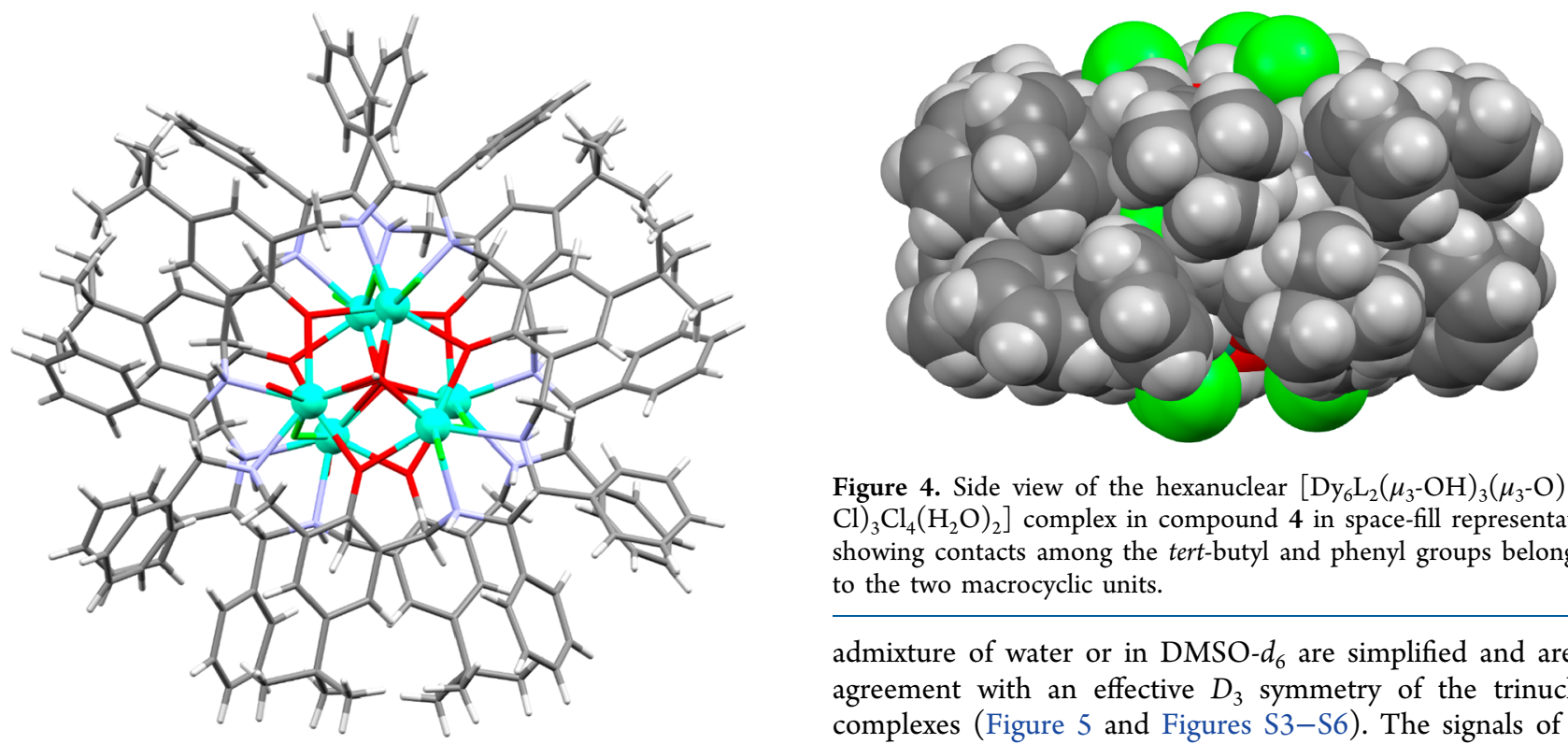

Figure 4. Side view of the hexanuclear $\left[\mathrm{Dy}_{6} \mathrm{~L}_{2}\left(\mu_{3}-\mathrm{OH}\right)_{3}\left(\mu_{3}-\mathrm{O}\right)\left(\mu_{2}-\right.\right.$ $\mathrm{Cl})_{3} \mathrm{Cl}_{4}\left(\mathrm{H}_{2} \mathrm{O}\right)_{2}$ ] complex in compound 4 in space-fill representation showing contacts among the tert-butyl and phenyl groups belonging to the two macrocyclic units.

admixture of water or in DMSO- $d_{6}$ are simplified and are in agreement with an effective $D_{3}$ symmetry of the trinuclear complexes (Figure 5 and Figures S3-S6). The signals of the

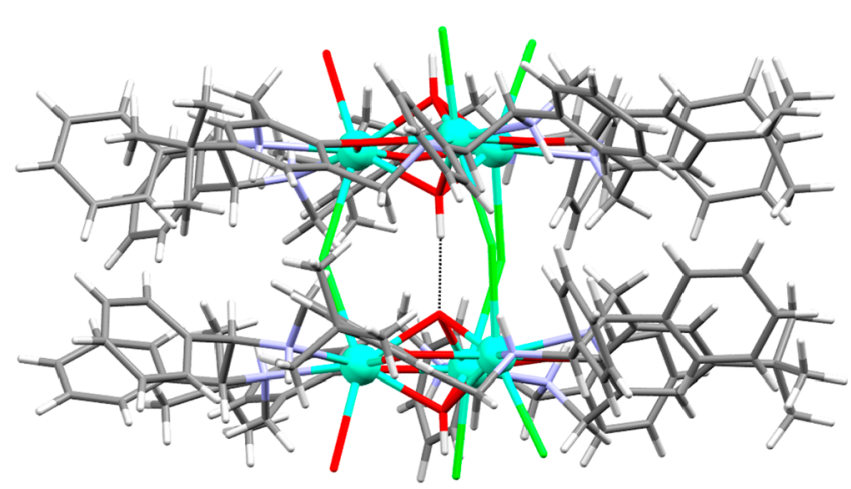

Figure 3. Top and side views of the hexanuclear $\left[\mathrm{Dy}_{6} \mathrm{~L}_{2}\left(\mu_{3}-\mathrm{OH}\right)_{3}\left(\mu_{3}\right.\right.$ $\left.\mathrm{O})\left(\mu_{2}-\mathrm{Cl}\right)_{3} \mathrm{Cl}_{4}\left(\mathrm{H}_{2} \mathrm{O}\right)_{2}\right]$ complex in compound 4 (disorder omitted).

dysprosium(III) and yttrium(III) ions, because these two ions possess very similar sizes and chemical properties. The difference in dimer formation more likely arises from the different structure of macrocycles $\mathrm{L}$ and $\mathrm{L}^{\prime}$, the former having a more extended hydrocarbon periphery. The trinuclear macrocyclic unit $\left[\mathrm{Dy}_{3} \mathrm{~L}\left(\mu_{3}-\mathrm{OH}\right)_{2}\right]^{4+}$ has a polar core and nonpolar periphery; organization of such units into dimers results in close contacts of the outer hydrocarbon parts of the two macrocycles and additional stabilization of the macrocyclic dimer via weak $\mathrm{C}-\mathrm{H} \cdots \pi$ interactions and other van der Waals interactions (Figure 4).

NMR and Circular Dichroism (CD) Spectra. The NMR spectra of the paramagnetic dysprosium(III) complexes in all solvents studied are complicated, and the signals are severely broadened, often beyond detection. To characterize the trinuclear complexes in solution, we have undertaken the study of the diamagnetic $\mathrm{Y}^{\mathrm{III}}$ derivative 3 , as well as the paramagnetic $\mathrm{Eu}^{\mathrm{III}}$ derivative 2 , because $\mathrm{Eu}^{\mathrm{III}}$ ions give rise to longer proton relaxation times in comparison with those with Dy ${ }^{\mathrm{II}}$ and hence narrower NMR lines. Nevertheless, the spectra of the $\left[\mathrm{Y}_{3} \mathrm{~L}\left(\mu_{3}-\mathrm{OH}\right)_{2}\left(\mathrm{NO}_{3}\right)_{3}\right] \mathrm{NO}_{3} \cdot 9 \mathrm{H}_{2} \mathrm{O}$ and $\left[\mathrm{Eu}_{3} \mathrm{~L}\left(\mu_{3}-\right.\right.$ $\left.\mathrm{OH})_{2}\left(\mathrm{NO}_{3}\right)_{3}\right] \mathrm{NO}_{3} \cdot 8 \mathrm{H}_{2} \mathrm{O}$ complexes in organic solvents such as $\mathrm{CD}_{3} \mathrm{OD}$ and $\mathrm{CDCl}_{3}$ are complicated and are not in accord with symmetrical complexes. On the other hand, the spectra recorded for these two complexes in methanol with a small

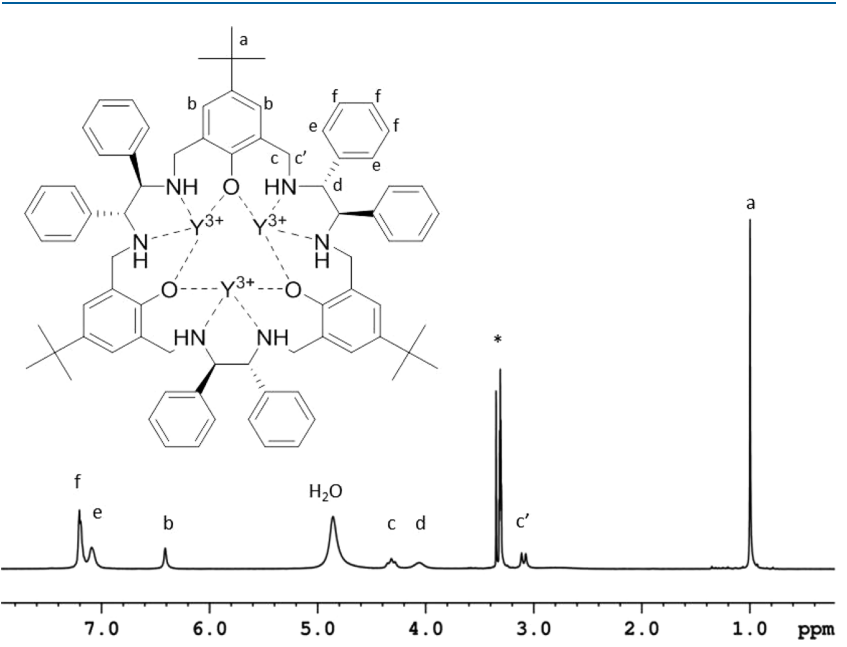

Figure 5. ${ }^{1} \mathrm{H}$ NMR spectrum of the $\left[\mathrm{Y}_{3} \mathrm{~L}\left(\mu_{3}-\mathrm{OH}\right)_{2}\left(\mathrm{NO}_{3}\right)_{3}\right] \mathrm{NO}_{3}$. $9 \mathrm{H}_{2} \mathrm{O}$ complex (3) $\left(500 \mathrm{MHz}, 300 \mathrm{~K}, \mathrm{CD}_{3} \mathrm{OD} / \mathrm{D}_{2} \mathrm{O}\right)$. The asterisk denotes the solvent signal.

diamagnetic yttrium(III) complex are clearly broadened by a dynamic process. Similarly, the signals of the paramagnetic europium(III) complex are broader than those observed for similar macrocyclic europium(III) complexes, indicating that this broadening is not due to only a paramagnetic effect. The main effect leading to effective $D_{3}$ symmetry is related to water coordination at axial positions. As indicated by the structures of crystals grown form methanol, the axial positions in the discussed trinuclear complexes are occupied by solvent molecules and by nitrate anions in a variable fashion. It is likely that in the mixed $\mathrm{CD}_{3} \mathrm{OD} / \mathrm{D}_{2} \mathrm{O}$ solvent water molecules are dominant axial ligands and that these molecules are exchanged in a dynamic process. This process is not fast enough for the dysprosium(III) derivatives $\left[\mathrm{Dy}_{3} \mathrm{~L}\left(\mu_{3}\right.\right.$ $\left.\mathrm{OH})_{2}\left(\mathrm{NO}_{3}\right)_{4}\left(\mathrm{H}_{2} \mathrm{O}\right)_{2}\right]$ and $\left[\mathrm{Dy}_{6} \mathrm{~L}_{2}\left(\mu_{3}-\mathrm{OH}\right)_{3}\left(\mu_{3}-\mathrm{O}\right)\left(\mu_{2}-\right.\right.$ $\left.\mathrm{Cl})_{3} \mathrm{Cl}_{4}\left(\mathrm{H}_{2} \mathrm{O}\right)_{2}\right]$ to result in a fast exchange regime on the NMR time scale because of much larger differences in chemical shifts for these complexes.

The variable-temperature ${ }^{1} \mathrm{H}$ NMR data for the $\left[\mathrm{Y}_{3} \mathrm{~L}\left(\mu_{3}\right.\right.$ $\left.\mathrm{OH})_{2}\left(\mathrm{NO}_{3}\right)_{3}\right] \mathrm{NO}_{3} \cdot 9 \mathrm{H}_{2} \mathrm{O}$ complex show that the signals 
observed at $300 \mathrm{~K}$ are averaged signals of less symmetrical species (Figure 6). At lower temperatures, at least two

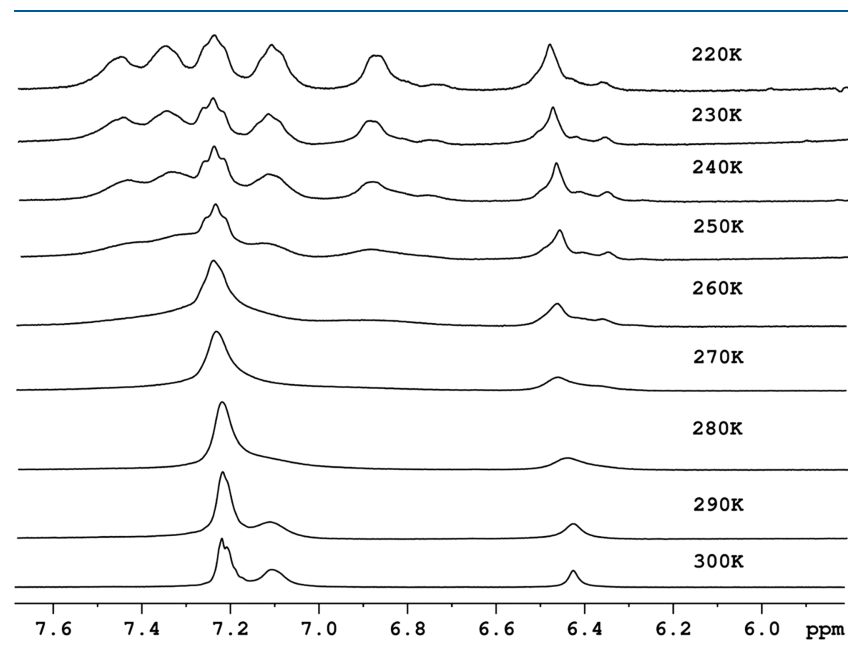

Figure 6. Temperature dependence of the ${ }^{1} \mathrm{H}$ NMR shifts of aromatic signals of the $\left[\mathrm{Y}_{3} \mathrm{~L}\left(\mu_{3}-\mathrm{OH}\right)_{2}\left(\mathrm{NO}_{3}\right)_{3}\right] \mathrm{NO}_{3} \cdot 9 \mathrm{H}_{2} \mathrm{O}$ complex $(500 \mathrm{MHz}$, $\left.\mathrm{CD}_{3} \mathrm{OD} / \mathrm{D}_{2} \mathrm{O}\right)$.

processes are indicated. The first one is a restricted rotation of phenyl rings giving rise to the observation of five main signals of these rings. The second effect is slowing axial ligand exchange, which gives rise to the observation of signals of minor species.

The chiral nature of the studied complexes is reflected in their CD spectra. This is illustrated by the spectra (Figure 7) of

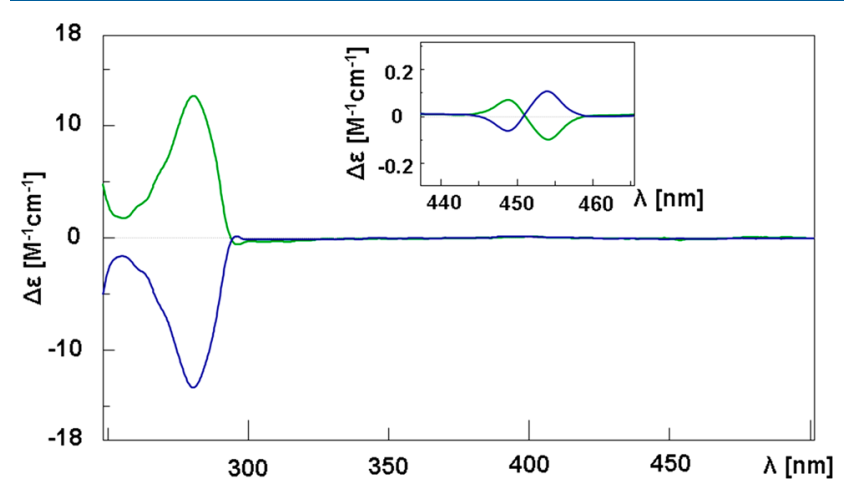

Figure 7. $\mathrm{CD}$ spectra $\left(\mathrm{CH}_{3} \mathrm{OH} / \mathrm{H}_{2} \mathrm{O}\right)$ of enantiomeric dysprosium(III) complexes $\mathbf{1}$ of the all- $R$ configuration (green) and $\mathbf{1 b}$ of the all$S$ configuration (blue).

dysprosium(III) complex $\mathbf{1}$ and enantiomeric complex $\mathbf{1 b}$, where the macrocyclic ligand is based on the $(1 S, 2 S)-1,2$ diphenylethylenediamine building blocks instead of $(1 R, 2 R)$ 1,2-diphenylethylenediamine. As expected, the two enantiomers give rise to mirror signals for the ligand transitions in the ultraviolet region; in addition, a weak $\mathrm{f}-\mathrm{f}$ transition is observed in the visible region. In comparison, the $\mathrm{CD}$ spectra of yttrium(III) complex 3 and enantiomeric complex $3 b$ (Figure S7) show similar ligand transitions but do not exhibit $\mathrm{f}-\mathrm{f}$ transitions as expected.

Magnetic Properties of Compounds 1 and 4. As some of the tri- and hexanuclear dysprosium clusters ${ }^{6,11,15,17}$ show SMM behavior, we were interested in studying the magnetic properties of compounds 1 and 4. The $\mathrm{dc}$ magnetic susceptibility data for compounds $\mathbf{1}$ and were collected in the temperature range of $1.8-300 \mathrm{~K}$ under a 1000 Oe field (Figure 8).

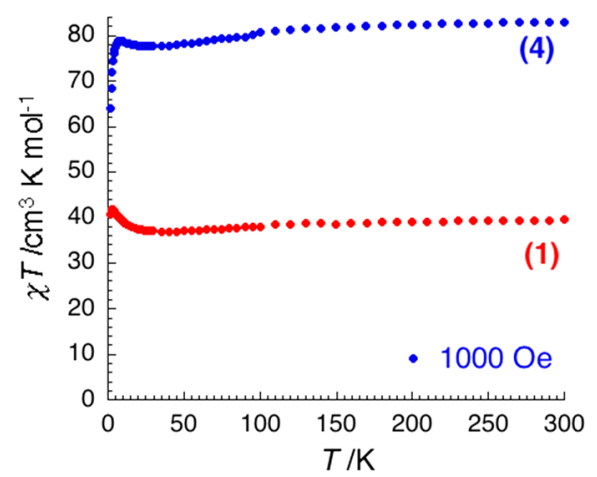

Figure 8. Plots of $\chi T$ vs $T$ for compounds 1 and 4 under a 1000 Oe dc field.

Compound $1\left[\mathrm{Dy}_{3} \mathrm{~L}\left(\mu_{3}-\mathrm{OH}\right)_{2}\left(\mathrm{NO}_{3}\right)_{4}\left(\mathrm{H}_{2} \mathrm{O}\right)_{2}\right] \cdot 5.8 \mathrm{CH}_{3} \mathrm{OH}$. At $300 \mathrm{~K}$, the $\chi T$ product of 1 is $39.48 \mathrm{~cm}^{3} \mathrm{~mol}^{-1} \mathrm{~K}$ (Figure 8 ), close to the expected value of $42.51 \mathrm{~cm}^{3} \mathrm{~mol}^{-1} \mathrm{~K}$ for three noncoupled dysprosium(III) metal ions $\left({ }^{6} \mathrm{H}_{15 / 2} ; \mathrm{S}={ }^{5} / 2, L=5\right.$, $\left.g={ }^{4} / 3\right)$. Upon cooling, the $\chi T$ product decreases smoothly to a value of $36.87 \mathrm{~cm}^{3} \mathrm{~mol}^{-1} \mathrm{~K}$ at $35 \mathrm{~K}$. Then the $\chi T$ product increases to a maximum value of $41.68 \mathrm{~cm}^{3} \mathrm{~mol}^{-1} \mathrm{~K}$ at $3.2 \mathrm{~K}$. This low-temperature increase suggests the presence of weak ferromagnetic exchange interaction between the constituent dysprosium(III) ions. ${ }^{10}$ Finally, the $\chi T$ product decreases to $40.72 \mathrm{~cm}^{3} \mathrm{~mol}^{-1} \mathrm{~K}$ at $1.8 \mathrm{~K}$, indicating the depopulation of excited Stark sublevels. ${ }^{16}$ Magnetization $(M)$ data were collected over the $0-70 \mathrm{kOe}$ field range at different temperatures. The nonsuperposition of the $M$ versus $H / T$ data (Figure S8) suggests the presence of a significant magnetic anisotropy and/or low-lying excited states. The magnetization increases rapidly at low field to reach a value of $16.64 \mu_{\mathrm{B}}$ at $70 \mathrm{kOe}$ (Figure S8) without clear saturation. This value is much lower than the expected saturation value of $\sim 30$ $\mu_{\mathrm{B}}$ for three noninteracting dysprosium(III) ions, most likely due to the crystal field effect at the dysprosium(III) ion that eliminates the 16-fold degeneracy of the ${ }^{6} \mathrm{H}_{15 / 2}$ ground state.

Due to the presence of magnetic anisotropy, slow relaxation of the magnetization for compound $\mathbf{1}$ was probed under a zero dc field using ac susceptibility measurements as a function of temperature at different frequencies. This compound exhibits a broad and relatively strong non-zero out-of-phase ac susceptibility signal (Figure S10). However, clear maxima for the out-of-phase signals could not be observed above $1.8 \mathrm{~K}$ at the maximum frequency of $1500 \mathrm{~Hz}$ that could be obtained on our SQUID, which could be the result of quantum tunneling resonance at a zero $\mathrm{dc}$ field or the presence of several relaxation processes with very close energy barriers and blocking temperatures. Nevertheless, the frequency-dependent out-of-phase ac susceptibility signals indicate that this compound exhibits slow magnetic relaxation, and to probe these further, measurements under different applied static (dc) fields were performed.

In cases in which zero-field quantum tunneling processes are dominant, the application of a dc field can shift the maxima of the out-of-phase signals into the frequency window available on most SQUIDs. Thus, to short-cut the quantum relaxation pathway in a zero field and to estimate the relaxation time 
above $1.8 \mathrm{~K}$, different $\mathrm{dc}$ fields were applied and the ac susceptibility was measured at $1.85 \mathrm{~K}$ (Figure 9).

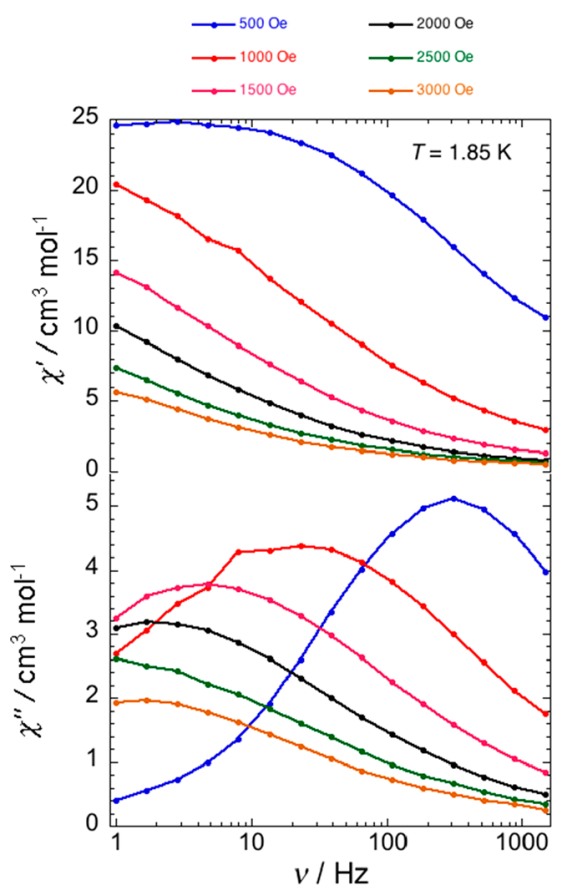

Figure 9. Frequency dependence of the real $\left(\chi^{\prime}\right.$, top) and imaginary $\left(\chi^{\prime \prime}\right.$, bottom $)$ components of the ac susceptibility for a polycrystalline sample of 1 at different dc fields between 500 and 3000 Oe at $1.85 \mathrm{~K}$. Solid lines are guides.

The out-of-phase and in-phase ac susceptibilities had a strong frequency dependence when an external dc field (Figure 10) was applied. The whole set of data $\left[\chi^{\prime \prime}\right.$ vs $\nu$ at different fields $(H)$ ] could be fitted using a generalized Debye model; ${ }^{18}$ therefore, the characteristic relaxation frequency was deduced from the maximum of the $\chi^{\prime \prime}$ versus $\nu$ data. An optimum field of $\sim 2500$ Oe was identified from these data (Figure S11). The ac susceptibility as a function of the frequency at different temperatures and as a function of the temperature at different frequencies has been thus measured at this optimum dc field (2500 Oe) to follow the temperature dependence of the relaxation time (Figure 10). This feature (shape and frequency dependence) demonstrates by itself that this compound is a SMM but that in a zero dc field the relaxation of the magnetization is too fast to be observed (probably due to QTM). Due to the broad shape of these curves, it is not very easy to find the maxima from $\chi^{\prime \prime}$ versus $\nu$. Therefore, the Cole-Cole plots were fitted by CC-Fit ${ }^{19}$ using a one-process Debye model and gave $\alpha$ values ranging from 0.50 to 0.56 at 2.4-5.5 K. No reasonable parameters were obtained using a two-process Debye model. The result indicates a wide distribution of the relaxation time or dual relaxation processes. The data extracted from the Cole-Cole plots were analyzed using an Arrhenius law. This law is valid for only these data between 4.0 and $5.5 \mathrm{~K}$ where we can find an energy barrier $U_{\text {eff }}$ of $10.6 \mathrm{~cm}^{-1}(15.2 \mathrm{~K})$ with a pre-exponential relaxation time, $\tau_{0}$, of $2.05 \times 10^{-4} \mathrm{~s}$ (Figure 11). The relaxation at low temperatures is not dominated by the Orbach process; thus, the relaxation process was fitted with the multiple-relaxation equation $\tau^{-1}=\tau_{0}^{-1} \exp \left(-U_{\text {eff }} / K_{\mathrm{B}} T\right)+C T^{n}+\tau_{\mathrm{QTM}}{ }^{-1}{ }^{20}$ The best fit gives an effective energy barrier $U_{\text {eff }}$ of $10.6 \mathrm{~cm}^{-1}(15.2$ $\mathrm{K})$, a $\tau_{0}$ of $2.05 \times 10^{-4} \mathrm{~s}$, a typical Raman exponent parameter $n$ of 3.6 , a $C$ of $0.58 \mathrm{~s}^{-1} \mathrm{~K}^{-3.6}$, and a $\tau_{\text {QTM }}$ of $4.5 \times 10^{-2} \mathrm{~s}$ (Figure 11).

Compound $4\left[\mathrm{Dy}_{6} \mathrm{~L}_{2}\left(\mu_{3}-\mathrm{OH}\right)_{3}\left(\mu_{3}-\mathrm{O}\right)\left(\mu_{2}-\mathrm{Cl}\right)_{3} \mathrm{Cl}_{4}\left(\mathrm{H}_{2} \mathrm{O}\right)_{2}\right]$. $3 \mathrm{CH}_{3} \mathrm{OH} \cdot 8 \mathrm{H}_{2} \mathrm{O}$. The temperature dependence of $\chi \mathrm{T}$ for 4 is broadly similar to that of $\mathbf{1}$ but with doubled values as a result of the presence of six rather than three dysprosium(III) ions.
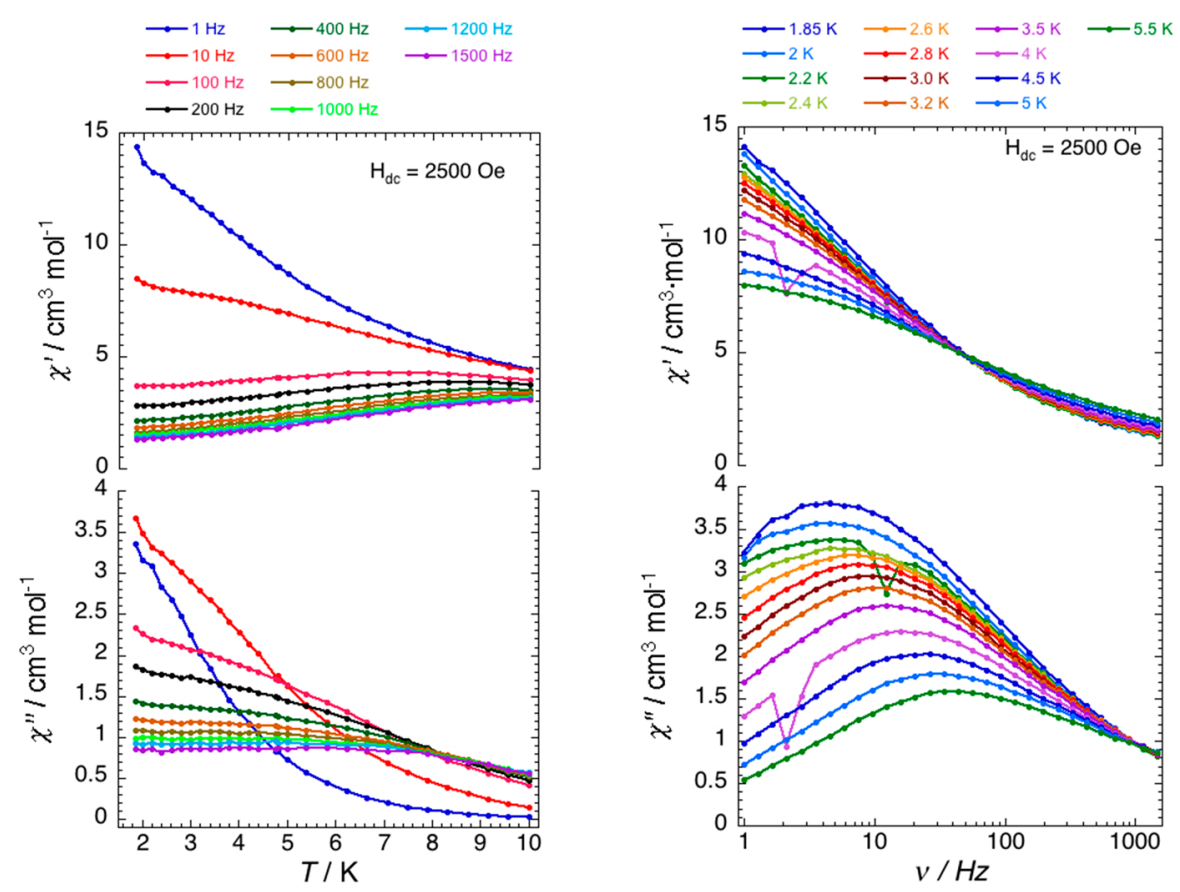

Figure 10. Temperature (left) and frequency (right) dependence of the real ( $\chi^{\prime}$, top) and imaginary ( $\chi^{\prime \prime}$, bottom) components of the ac susceptibility at different ac frequencies between 1 and $1500 \mathrm{~Hz}$ and different temperatures between 1.8 and $10 \mathrm{~K}$, respectively, with a 3 Oe ac field for a polycrystalline sample of 1 in a 2500 Oe dc field. 

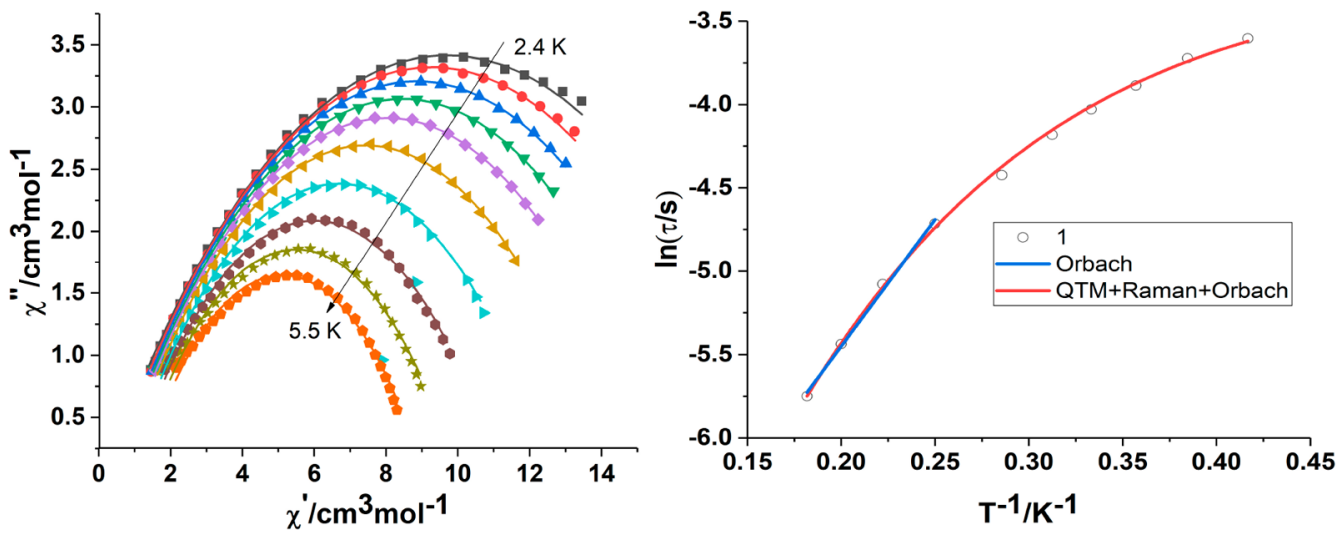

Figure 11. Cole-Cole plots of 1 at the indicated temperatures (solid lines for fitting) (left) and temperature dependence of the magnetization relaxation time as $\tau$ vs $T^{-1}$ for 1 at a 2500 Oe dc field (right). The blue line indicates the Orbach process, and the red line the QTM, Raman, and Orbach processes.

The $\chi T$ value of $82.87 \mathrm{~cm}^{3} \mathrm{~mol}^{-1} \mathrm{~K}$ at $300 \mathrm{~K}$ is in line with the expected value of $85.02 \mathrm{~cm}^{3} \mathrm{~mol}^{-1} \mathrm{~K}$ for six independent dysprosium(III) ions. The $\chi T$ value decreases steadily to reach $78.23 \mathrm{~cm}^{3} \mathrm{~K} \mathrm{~mol}^{-1}$ at $50 \mathrm{~K}$ (Figure 8) and then increases to a maximum value of $78.81 \mathrm{~cm}^{3} \mathrm{~mol}^{-1} \mathrm{~K}$ at $8.4 \mathrm{~K}$. This lowtemperature increase suggests the presence of weak ferromagnetic exchange interaction between the constituent dysprosium(III) ions. ${ }^{11 \mathrm{~h}}$ With a further decrease in temperature, the $\chi T$ drops abruptly to a minimum value of $63.98 \mathrm{~cm}^{3}$ $\mathrm{K} \mathrm{mol}^{-1}$ at $1.85 \mathrm{~K}$, indicating depopulation of excited Stark sublevels.

The magnetization for complex 4 at different temperatures $(2-5 \mathrm{~K})$ reaches a maximum value of $35.11 \mu_{\mathrm{B}}$ at $70 \mathrm{kOe}$, without showing true saturation (Figure S9). This is noticeably lower than the theoretical value for six dysprosium(III) ions $\left(\sim 60 \mu_{\mathrm{B}}\right)$, indicating a much smaller effective spin and also significant magnetic anisotropy in $\mathbf{4}$, and is in line with what has been observed in other $\mathrm{Dy}_{6}$ systems. ${ }^{13}$

Due to the presence of magnetic anisotropy, the magnetization relaxation of $\mathbf{4}$ has also been probed under zero dc fields using ac susceptibility measurements as a function of temperature at different frequencies (Figure S12). Both inphase and out-of-phase components of ac susceptibility are strongly frequency-dependent below $12 \mathrm{~K}$ for ac frequencies of $\leq 1500 \mathrm{~Hz}$ as expected in the presence of the slow relaxation of the magnetization. A clear maximum of the out-of-phase signal could not be observed above $1.8 \mathrm{~K}$ even at a frequency of 1500 $\mathrm{Hz}$ (Figure S12), and again the behavior was probed further by performing measurements with applied dc fields at $1.85 \mathrm{~K}$ (Figure 12). From these ac measurements and the field variation of the characteristic frequency, it was found that quantum effects are minimized around 3000 Oe as shown by the minimum of the characteristic frequency of the system at this dc field (Figure S13). Therefore, the ac susceptibility was measured at $3000 \mathrm{Oe}$ at different temperatures and ac frequencies (Figure 13). To inspect the distribution of the relaxation time, the Cole-Cole plots were scrutinized for compound 4 (Figure 14, left) using CC-Fit software. ${ }^{19}$ The data can be fitted using a generalized Debye model with $\alpha$ values in the range of $0.50-0.57$ (Supporting Information) at 3.0-5.5 K, which indicates a wide distribution of relaxation times or dual relaxation processes. No reasonable parameters were obtained using a two-process Debye model. The relaxation times extracted from CC-Fit were used to construct the Arrhenius plot shown in the right panel of Figure 14. A

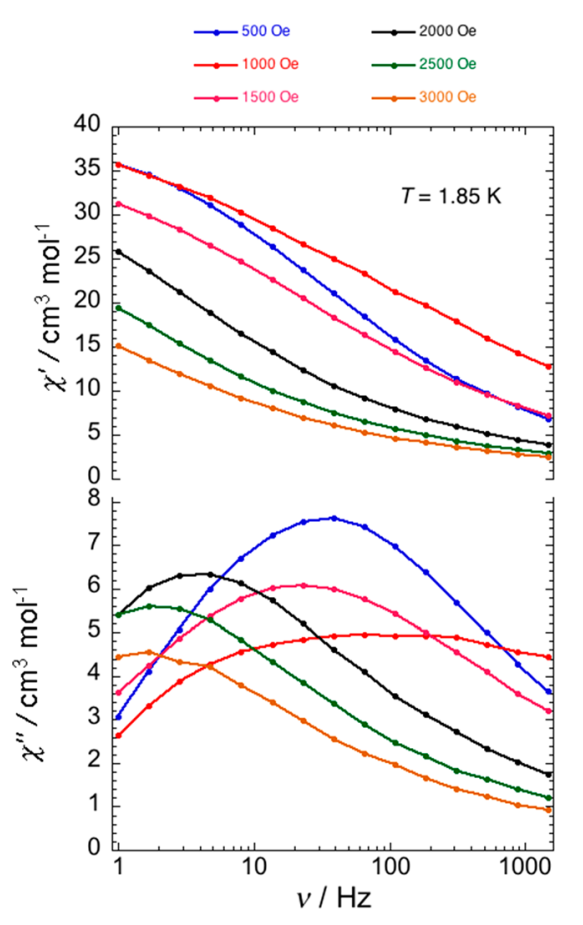

Figure 12. Frequency dependence of the real $\left(\chi^{\prime}\right.$, top) and imaginary ( $\chi^{\prime \prime}$, bottom) components of the ac susceptibility for a polycrystalline sample of 4 at different dc fields between 500 and 3000 Oe at $1.85 \mathrm{~K}$. Solid lines are guides.

thermally activated behavior with an energy barrier of $\sim 7.9$ $\mathrm{cm}^{-1}(11.4 \mathrm{~K})$ and a pre-exponential factor $\tau_{0}$ of $\sim 1.68 \times 10^{-4}$ $\mathrm{s}$ can be found.

The type of behavior seen for $\mathbf{1}$ and $\mathbf{4}$ has been identified as an intrinsic property of some molecules containing several magnetic centers. ${ }^{11,13,15}$ For some $\mathrm{Dy}_{3}$ and $\mathrm{Dy}_{6}$ systems, toroidal moments have been identified, ${ }^{1,13}$ and we checked for this possibility by plotting $\mathrm{d} M / \mathrm{d} H$ for compounds $\mathbf{1}$ and $\mathbf{4}$ (Figure S14). The lack of maxima for these indicates the absence of toroidicity. ${ }^{13 \mathrm{i}}$

\section{CONCLUSIONS}

The new $3+3$ chiral macrocycle $L$ based on $(1 R, 2 R)-1,2$ diphenylethylenediamine is able to bind rare earth $(\mathrm{Dy}, \mathrm{Eu}$, or $\mathrm{Y}$ ) ions. The X-ray crystal structures of the obtained complexes indicate the presence of trinuclear hydroxo-bridged clusters in 

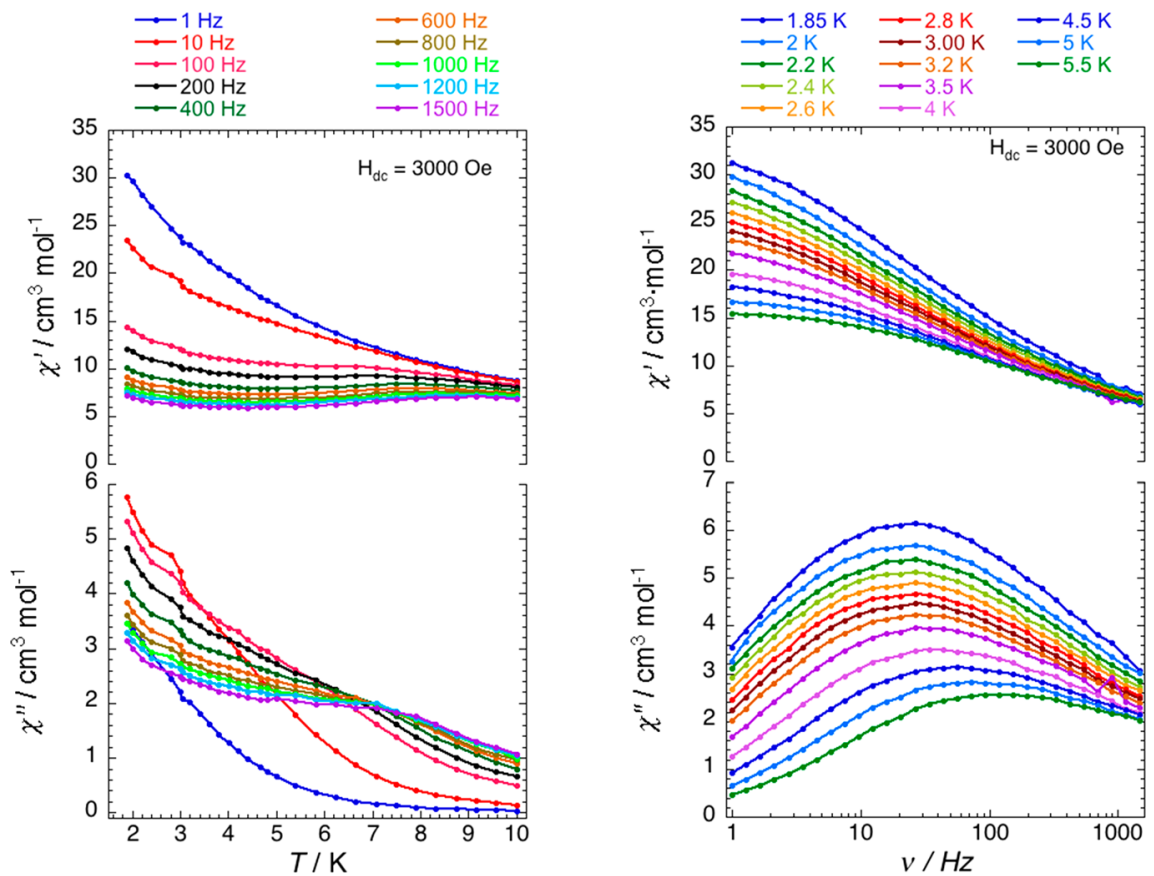

Figure 13. Temperature (left) and frequency (right) dependence of the real $\left(\chi^{\prime}\right.$, top) and imaginary $\left(\chi^{\prime \prime}\right.$, bottom) components of the ac susceptibility at different ac frequencies between 1 and $1500 \mathrm{~Hz}$ and different temperatures between 1.8 and $10 \mathrm{~K}$, respectively, with a 3 Oe ac field for a polycrystalline sample of $\mathbf{4}$ in a 3000 Oe dc field.
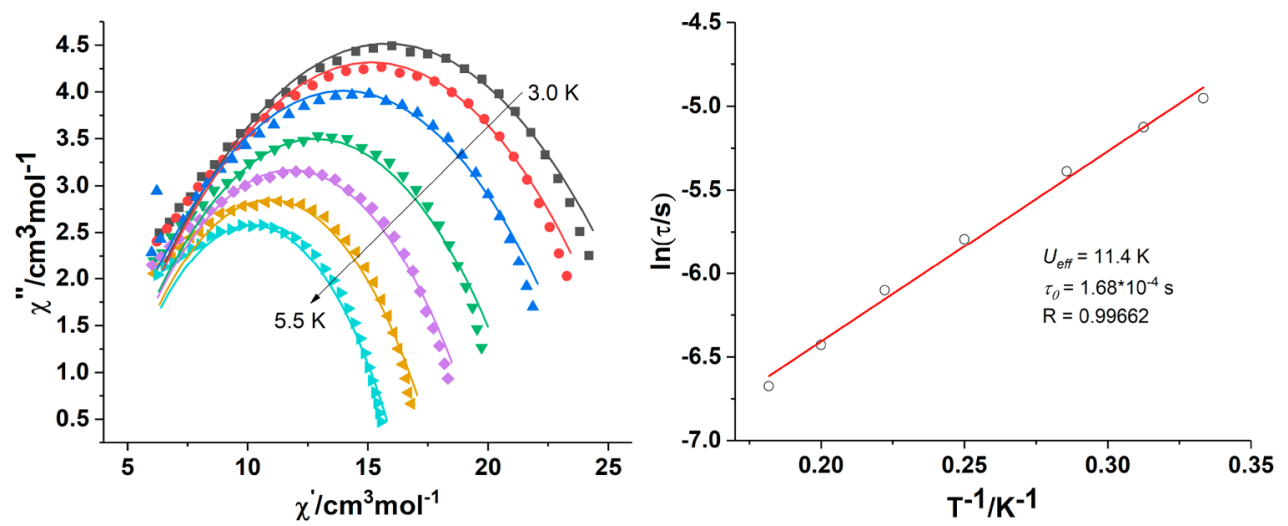

Figure 14. Cole-Cole plots of 4 at the indicated temperatures (solid lines for fitting, left) and temperature dependence of the magnetization relaxation time as $\tau$ vs $T^{-1}$ for 4 at a 3000 Oe dc field (right).

the center of the macrocycle. The replacement of nitrate counteranions by chloride anions results in a profound structural change, i.e., dimerization of the trinuclear macrocyclic units via chloride bridges and an $\mathrm{O}-\mathrm{H} \cdots \mathrm{O}$ bond. The solid-state structures also show the presence of variable sets of additional axial ligands (solvent molecules or anions), while NMR spectra indicate dynamic exchange of these axial ligands in solution. The magnetic studies of the trinuclear dysprosium(III) compound $\mathbf{1}$ and hexanuclear dysprosium(III) compound 4 suggest the weak ferromagnetic interactions between neighboring metal ions. In addition, compounds 1 and 4 show slow relaxation, which suggests SMM behavior.

\section{EXPERIMENTAL SECTION}

Synthesis. The 3+3 Macrocyclic Schiff Base Precursor $\mathrm{H}_{3} L^{\prime \prime}$. The solution of $2.06 \mathrm{~g}$ (10 mmol) of $(1 R, 2 R)$-1,2-diphenylethylenediamine in $50 \mathrm{~mL}$ of acetonitrile was combined with the solution of 2.12 $\mathrm{g}(10 \mathrm{mmol})$ of 2,6-diformyl-4-tert-butylphenol in $30 \mathrm{~mL}$ of acetonitrile. The mixture was vigorously stirred for $45 \mathrm{~min}$, and the yellow precipitate was filtered, washed with $20 \mathrm{~mL}$ of cold acetonitrile, and dried. Yield: $89 \%, 3.47$ g. Anal. Calcd for $\mathrm{C}_{78} \mathrm{H}_{80} \mathrm{~N}_{6} \mathrm{O}_{4}: \mathrm{N}, 7.21$; C, 80.36; H, 6.92. Found: N, 7.21; C, 80.56; H, 6.93. ESI-MS: L + $\mathrm{H}^{+}$ $m / z$ 1147.6, $\mathrm{L}+2 \mathrm{H}^{+} \mathrm{m} / z$ 574.3. ${ }^{1} \mathrm{H}$ NMR $\left(\mathrm{CDCl}_{3}, 500 \mathrm{MHz}\right): \delta_{\mathrm{H}}$ $1.22(27 \mathrm{H}, \mathrm{s}), 1.66(\mathrm{NH}, \mathrm{s}), 4.74(3 \mathrm{H}, \mathrm{d}, J=9.25 \mathrm{~Hz}), 4.81(3 \mathrm{H}, \mathrm{d}, J$ $=9.25 \mathrm{~Hz}), 7.07-7.22(30 \mathrm{H}+3 \mathrm{H}, \mathrm{m}), 8.04(3 \mathrm{H}, \mathrm{s}), 8.45(3 \mathrm{H}, \mathrm{s})$, $8.89(3 \mathrm{H}, \mathrm{s}), 13.86(3 \mathrm{H}, \mathrm{s})$.

The enantiomeric $3+3$ macrocyclic Schiff base precursor $\mathrm{H}_{3} \mathrm{~L}^{\prime \prime} \mathrm{b}$ has been prepared in an analogous way starting from (1S,2S)-1,2diphenylethylenediamine instead of $(1 R, 2 R)$-1,2-diphenylethylenediamine.

Macrocycle $\mathrm{H}_{3}$ L. First, $3.0 \mathrm{~g}(2.6 \mathrm{mmol})$ of the precursor macrocycle $\mathrm{H}_{3} \mathrm{~L}^{\prime \prime}$ was dissolved in the chloroform/methanol mixture. The solution was placed on an ice bath, and $1.2 \mathrm{~g}(31 \mathrm{mmol})$ of solid sodium borohydride was gradually added under a $\mathrm{N}_{2}$ atmosphere. The mixture was warmed to room temperature, stirred for $24 \mathrm{~h}$, and evaporated to dryness. The residue was suspended in water and extracted with chloroform. The organic phase was evaporated to dryness. Yield: $2.41 \mathrm{~g}, 75 \%, 1.93 \mathrm{mmol}, 2.41 \mathrm{~g}$. Anal. Calcd for $\mathrm{C}_{78} \mathrm{H}_{90} \mathrm{~N}_{6} \mathrm{O}_{3} \cdot{ }^{3} /{ }_{4} \mathrm{CHCl}_{3} \cdot{ }_{1}{ }_{2} \mathrm{H}_{2} \mathrm{O}: \mathrm{N}, 6.68 ; \mathrm{C}, 75.18 ; \mathrm{H}, 7.35$. Found: $\mathrm{N}, 6.50 ; \mathrm{C}, 75.17$; H, 7.32. ESI-MS: $m / z 1159.7\left\{\mathrm{H}_{3} \mathrm{~L}^{\prime \prime}+\mathrm{H}^{+}\right\}^{+} .{ }^{1} \mathrm{H}$ 
NMR $\left(\mathrm{CDCl}_{3}, 500 \mathrm{MHz}\right): \delta_{\mathrm{H}} 1.13(27 \mathrm{H}, \mathrm{s}), 2.76(6 \mathrm{H}, \mathrm{s}), 3.60(6 \mathrm{H}$, d, $J=13.26 \mathrm{~Hz}), 3.81(6 \mathrm{H}, \mathrm{d}, J=13.26 \mathrm{~Hz}), 3.85(6 \mathrm{H}, \mathrm{s}), 6.73(6 \mathrm{H}$, s), $7.12(30 \mathrm{H}, \mathrm{m}), 10.51(3 \mathrm{H}, \mathrm{s})$.

The enantiomeric macrocycle $\mathrm{H}_{3} \mathrm{Lb}$ has been prepared in an analogous way starting from $\mathrm{H}_{3} \mathrm{~L}$ "b.

$\left[D y_{3} L\left(\mu_{3}-\mathrm{OH}\right)_{2}\left(\mathrm{NO}_{3}\right)_{3}\right] \mathrm{NO}_{3} \cdot 8 \mathrm{H}_{2} \mathrm{O}$ (1). First, $115.9 \mathrm{mg}(0.1 \mathrm{mmol})$ of $\mathrm{H}_{3} \mathrm{~L}$ was dissolved in $5 \mathrm{~mL}$ of methanol and mixed with the solution of $131.6 \mathrm{mg}(0.3 \mathrm{mmol})$ of $\mathrm{Dy}\left(\mathrm{NO}_{3}\right)_{3} \cdot 5 \mathrm{H}_{2} \mathrm{O}$ under a $\mathrm{N}_{2}$ atmosphere. Then, $50.6 \mathrm{mg}(0.5 \mathrm{mmol})$ of trietylamine was added to the resulting clear yellow solution, the mixture stirred for $30 \mathrm{~min}$, and the solution left to stand for $48 \mathrm{~h}$. The formed colorless crystals of X-ray quality were collected and dried in air. Yield: $124 \mathrm{mg}, 61 \%$. Anal. Calcd for $\mathrm{C}_{78} \mathrm{H}_{105} \mathrm{~N}_{10} \mathrm{O}_{25} \mathrm{Dy}_{3}$ : C, 45.25; N, 6.77; H, 5.11. Found: $\mathrm{C}, 44.83 ; \mathrm{N}$, 6.55; H, 5.15. ${ }^{1} \mathrm{H}$ NMR (95:5 MeOD: $\left.\mathrm{D}_{2} \mathrm{O}, 500 \mathrm{MHz}\right): \delta_{\mathrm{H}} 22.6,28.9$, 52.2, 62.7, 74.4. ESI-MS: $m / z$ 901.2 $\left[\mathrm{Dy}_{3} \mathrm{~L}\left(\mu_{3}-\mathrm{OH}\right)_{2}\left(\mathrm{NO}_{3}\right)_{2}\right]^{2+}$.

The enantiomeric complex $\mathbf{1 b}$ has been prepared in an analogous way starting from macrocycle $\mathrm{H}_{3} \mathrm{Lb}$.

$\left[E u_{3} \mathrm{~L}\left(\mu_{3}-\mathrm{OH}\right)_{2}\left(\mathrm{NO}_{3}\right)_{3}\right] \mathrm{NO}_{3} \cdot 8 \mathrm{H}_{2} \mathrm{O}$ (2). The title compound was obtained in a similar fashion in $54 \%$ yield $(106 \mathrm{mg})$. Anal. Calcd for $\mathrm{C}_{78} \mathrm{H}_{105} \mathrm{~N}_{10} \mathrm{O}_{25} \mathrm{Eu}_{3}: \mathrm{N}, 6.80 ; \mathrm{C}, 46.09 ; \mathrm{H}, 5.27$. Found: $\mathrm{N}, 6.65 ; \mathrm{C}$, 46.12; H, 4.77. ESI-MS: $m / z 885.2\left[\mathrm{Eu}_{3} \mathrm{~L}\left(\mu_{3}-\mathrm{OH}\right)_{2}\left(\mathrm{NO}_{3}\right)_{2}\right]^{2+} .{ }^{1} \mathrm{H}$ NMR (95:5 MeOD: $\left.\mathrm{D}_{2} \mathrm{O}, 500 \mathrm{MHz}\right): \delta_{\mathrm{H}}-19.72,-17.38,-8.38$, $-1.90,-0.98,4.50,4.89,26.18$.

$\left[\mathrm{Y}_{3} \mathrm{~L}\left(\mu_{3}-\mathrm{OH}\right)_{2}\left(\mathrm{NO}_{3}\right)_{3}\right] \mathrm{NO}_{3} \cdot 9 \mathrm{H}_{2} \mathrm{O}$ (3). The title compound was obtained in a similar fashion in $51.4 \%$ yield $(96 \mathrm{mg})$. Anal. Calcd for $\mathrm{C}_{78} \mathrm{H}_{107} \mathrm{~N}_{10} \mathrm{O}_{26} \mathrm{Y}_{3}$ : N, 7.50; C, 50.17; H, 5.78. Found: N, 7.42; C, 50.21; H, 5.71. ${ }^{1} \mathrm{H}$ NMR (95:5 MeOD: $\left.\mathrm{D}_{2} \mathrm{O}, 300 \mathrm{MHz}\right): \delta_{\mathrm{H}} 1.00$ $(27 \mathrm{H}, \mathrm{s}), 2.77(\mathrm{NH}), 3.09(6 \mathrm{H}, \mathrm{d}, J=11.9 \mathrm{~Hz}), 4.06(6 \mathrm{H}, \mathrm{d}, J=6.4$ $\mathrm{Hz}), 4.32(6 \mathrm{H}, \mathrm{t}, J=10.1 \mathrm{~Hz}), 6.41(6 \mathrm{H}, \mathrm{s}), 7.09(12 \mathrm{H}, \mathrm{m}), 7.20$ $(18 \mathrm{H}, \mathrm{m})$. ESI-MS: $\mathrm{m} / z$ 790.2 $\left[\mathrm{Y}_{3} \mathrm{~L}\left(\mu_{3}-\mathrm{OH}\right)_{2}\left(\mathrm{NO}_{3}\right)_{2}\right]^{2+}, 1642.4$ $\left[\mathrm{Y}_{3} \mathrm{~L}\left(\mu_{3}-\mathrm{OH}\right)_{2}\left(\mathrm{NO}_{3}\right)_{3}\right]^{+}$.

The enantiomeric complex $\mathbf{3} \mathbf{b}$ has been prepared in an analogous way starting from the all-S macrocycle $\mathrm{H}_{3} \mathrm{Lb}$.

The deuterated form of complex $3, d_{6}-\left[\mathrm{Y}_{3} \mathrm{~L}\left(\mu_{3}-\mathrm{OH}\right)_{2}\left(\mathrm{NO}_{3}\right)_{3}\right] \mathrm{NO}_{3}$. $9 \mathrm{H}_{2} \mathrm{O}$, with deuterated amine positions was prepared in deuterated methanol first by stirring $\mathrm{H}_{3} \mathrm{~L}$ for $5 \mathrm{~h}$ in $\mathrm{CD}_{3} \mathrm{OD}$ and then proceeding in analogous way as for nondeuterated 3.

$\left[D y_{6} L_{2}\left(\mu_{3}-\mathrm{OH}\right)_{3}\left(\mu_{3}-\mathrm{O}\right)\left(\mu_{2}-\mathrm{Cl}\right)_{3} \mathrm{Cl}_{4}\left(\mathrm{H}_{2} \mathrm{O}\right)_{2}\right] \cdot 14 \mathrm{H}_{2} \mathrm{O}$ (4). The title compound was obtained in a similar fashion as the nitrate derivative starting form $\mathrm{DyCl}_{3} \cdot 6 \mathrm{H}_{2} \mathrm{O}$. Yield: $112 \mathrm{mg}, 58 \%$. Anal. Calcd for $\mathrm{C}_{156} \mathrm{H}_{205} \mathrm{Cl}_{7} \mathrm{~N}_{12} \mathrm{O}_{24} \mathrm{Dy}_{6}: \mathrm{N}, 4.36 ; \mathrm{C}, 48.60 ; \mathrm{H}, 5.36$. Found: $\mathrm{N}, 4.21$; C, 48.52; H, 5.13. ESI-MS: $m / z 892.2\left[\mathrm{Dy}_{3} \mathrm{~L}\left(\mu_{3}-\mathrm{OH}\right)_{2} \mathrm{Cl}_{2}\left(\mathrm{H}_{2} \mathrm{O}\right)_{2}\right]^{2+}$, $874.2\left[\mathrm{Dy}_{3} \mathrm{~L}\left(\mu_{3}-\mathrm{OH}\right)_{2} \mathrm{Cl}_{2}\right]^{2+}$. ${ }^{1} \mathrm{H}$ NMR (95:5 MeOD: $\mathrm{D}_{2} \mathrm{O}, 500$ $\mathrm{MHz}): \delta_{\mathrm{H}} 22.8,28.7,48.3,55.5,59.3,70.0$.

Measurements. The NMR spectra were recorded on a Bruker Avance 500 spectrometer. The CD spectra were measured on a Jasco J-715 spectropolarimeter. MS data were obtained on Bruker microOTOF-Q and apex ultra FT-ICR instruments using positive electrospray ionization mode. The elemental analyses were carried out on a PerkinElmer $2400 \mathrm{CHN}$ elemental analyzer.

The dc magnetic susceptibility measurements were carried out with a Quantum Design MPMS XL-7 SQUID magnetometer in the temperature range of $1.8-300 \mathrm{~K}$ with applied magnetic fields of 1000 Oe on crushed crystalline samples of complex 1 and complex 4, with masses of 18.84 and $13.82 \mathrm{mg}$, respectively. To prevent the torqueing, the samples were restrained in a drop of Paratone-N oil $(7.81 \mathrm{mg}$ for complex 1 and $5.34 \mathrm{mg}$ for complex 4). The ac susceptibility measurements in a zero dc field and a dc field of 2500 Oe (for 1) and 3000 Oe (for 4) were performed under a 3 Oe ac field oscillating at frequencies from 1 to $1500 \mathrm{~Hz}$. All data were corrected for the sample holders and Paratone- $\mathrm{N}$ oil previously measured and for the diamagnetic contributions of the samples as deduced by using Pascal's constant tables.

Crystallographic Studies. Crystals of 1-4 Were Grown from Methanol. The crystallographic measurements were performed at $100(2)-130(2) \mathrm{K}$ on $\kappa$-geometry four-circle diffractometers with graphite-monochromatized Mo K $\alpha$ radiation (see details in Table 1). Data were corrected for Lorentz and polarization effects. Data collection, cell refinement, data reduction, and analysis were carried out with CrysAlis PRO or CrysAlis CCD and CrysAlis RED, respectively. ${ }^{21}$ Analytical or empirical (multiscan) absorption correction was applied to the data using CrysAlis PRO or CrysAlis RED.

Structures of $\mathbf{2}$ and $\mathbf{4}$ were determined by direct methods using the SHELXS-97 program ${ }^{22}$ and refined on $F^{2}$ by a full-matrix least-squares technique using SHELXL-2014 $4^{23}$ with anisotropic thermal parameters for the ordered and fully occupied non-H atoms. Structures of $\mathbf{1}$ and 3 are isomorphous with 2 ; therefore, their refinements were started by using the coordinates of ordered heavy atoms taken from the europium complex. Some of the partially occupied positions were also refined anisotropically.

High maxima close to the $\mathrm{Ln}^{\mathrm{III}}$ atoms were observed in the final difference Fourier maps of $\mathbf{1}$ and $\mathbf{2}$. Therefore, their finally accepted models assume Ln atoms slightly disordered over three (for Dy in 1) and four (for Eu in 2) sites [SOFs of 0.925(2), 0.0419(14), and $0.0333(12)$ in 1 and 0.878(4), 0.054(3), 0.040(3), and 0.030(2) in $2]$. The respective $\mathrm{Ln}$ positions were refined with linear restraints applied to their occupancies, with the SOFs summing to unity (SUMP instruction in SHELXL-2014).

Dimeric complex in 4 lies in a special position, on a 2 -fold axis, with one macrocyclic trinuclear unit with its axial ligands in the asymmetric part (one of three bridging chloride anions lies on the 2-fold axis). Dysprosium(III) cations from the two macrocyclic clusters are linked by the $\mathrm{Cl}^{-}$anions, and the additional linking is provided by $\mathrm{O}-\mathrm{H} \cdots \mathrm{O}$ interaction formed between the $\mathrm{OH}$ group from one unit and $\mathrm{O}^{2-}$ from the other. Thus, the hydroxyl $\mathrm{H}$ atom position was refined with a SOF of 0.5 , and the model assumes the presence of $\mathrm{Dy}_{3}\left(\mu_{3}-\mathrm{OH}\right)_{2}$ and $\mathrm{Dy}_{3}\left(\mu_{3}-\mathrm{OH}\right)\left(\mu_{3}-\mathrm{O}\right)$ clusters in the two macrocyclic units of the dimer. Two of three positions of the outer axial ligands in each monomeric unit are disordered and are occupied by water molecules and chloride anions, each with a SOF of $\sim 0.5$. In the final model, the positions of partially occupied chloride anions were refined with linear restraints applied to their occupancies, with the SOFs summing to unity (SUMP instructions). The final accepted formula for 4 is $\left[\mathrm{Dy}_{6} \mathrm{~L}_{2}\left(\mu_{3^{-}}\right.\right.$ $\left.\mathrm{OH})_{3}\left(\mu_{3}-\mathrm{O}\right)\left(\mu_{2}-\mathrm{Cl}\right)_{3} \mathrm{Cl}_{4}\left(\mathrm{H}_{2} \mathrm{O}\right)_{2}\right] \cdot 3 \mathrm{CH}_{3} \mathrm{OH} \cdot 8 \mathrm{H}_{2} \mathrm{O}$, although the type and number of solvent molecules should be treated as a rough approximation.

In addition, some of the groups in 1-4 were found to be disordered (one $t-\mathrm{Bu}$, two nitrate ions, and one $\mathrm{MeOH}$ molecule in $\mathbf{1}$, two $t$ - $\mathrm{Bu}$ groups, two $\mathrm{NO}_{3}{ }^{-}$ions, and two $\mathrm{MeOH}$ molecules in 2, one $t$ - $\mathrm{BuPh}$, one phenyl, one nitrate, and one $\mathrm{MeOH}$ in 3 , and one phenyl in 4) and refined isotropically in two positions each, with SOFs of the respective position given in the CIF file deposited at the Cambridge Crystallographic Data Centre (Table 1). Some of the positions of $\mathrm{MeOH}$ molecules in 1-3 and most of the positions of water $\mathrm{O}$ atoms in $\mathbf{4}$ are not fully occupied.

All $\mathrm{H}$ atoms in 1-4 were included using geometrical considerations or were found in difference Fourier maps. In the final refinement cycles, all $\mathrm{C}$ - and $\mathrm{N}$-bound $\mathrm{H}$ atoms as well as hydroxyl $\mathrm{H}$ atoms were repositioned in their calculated positions and refined using a riding model, with $\mathrm{O}-\mathrm{H}$ distances of $0.84-1.00 \AA, \mathrm{N}-\mathrm{H}$ distances of 1.00 $\AA$, and $\mathrm{C}-\mathrm{H}$ distances of $0.95-1.00 \AA$ and with $U_{\text {iso }}(\mathrm{H})=$ $1.2 U_{\text {eq }}(\mathrm{O}, \mathrm{N}, \mathrm{C})$ for $\mu_{3} \mathrm{OH}, \mathrm{NH}, \mathrm{CH}$, and $\mathrm{CH}_{2}$ and $U_{\text {iso }}(\mathrm{H})=$ $1.5 U_{\text {eq }}(\mathrm{O}, \mathrm{C})$ for $\mathrm{MeOH}$ and $\mathrm{CH}_{3}$. Water $\mathrm{H}$ atoms in $\mathbf{1 - 3}$ were refined with $\mathrm{O}-\mathrm{H}$ bond lengths restrained to $0.840(2) \AA$ and with $U_{\text {iso }}(\mathrm{H})=1.5 U_{\text {eq }}(\mathrm{O})$ and were then constrained to ride on their parent atoms (AFIX 3 instructions). Additionally, the $\mathrm{H} \cdots \mathrm{H}$ distances in the water molecules were restrained to 1.380 (2) A. Water $\mathrm{H}$ atoms in 4 were not found in difference Fourier maps.

Some geometrical restraints (DFIX, SAME instructions), restraints on anisotropic displacement parameters (SIMU instructions), and constraints on the fractional coordinates and anisotropic displacement parameters (EXYZ and EADP instructions) were applied in the refinement procedures if appropriate. Figures presenting the molecular structures were made using the Mercury program. ${ }^{24}$ Details are given in the crystallographic information files deposited at the Cambridge Crystallographic Data Centre. Metric parameters for the coordination polyhedra of the selected metal centers (Dy in $\mathbf{1}$ and Dy in 4) were analyzed using SHAPE. ${ }^{14}$ 


\section{ASSOCIATED CONTENT}

\section{S Supporting Information}

The Supporting Information is available free of charge on the ACS Publications website at DOI: 10.1021/acs.inorgchem.8b03266.

Figures S1-S9 (NMR spectra and magnetic data) (PDF)

\section{Accession Codes}

CCDC 1501188-1501191 contain the supplementary crystallographic data for this paper. These data can be obtained free of charge via www.ccdc.cam.ac.uk/data_request/cif, or by emailingdata_request@ccdc.cam.ac.uk, or by contacting The Cambridge Crystallographic Data Centre, 12 Union Road, Cambridge CB2 1EZ, UK; fax: +44 1223336033.

\section{AUTHOR INFORMATION}

\section{Corresponding Authors}

*E-mail: jerzy.lisowski@chem.uni.wroc.pl.

*E-mail: annie.powell@kit.edu.

\section{ORCID}

Katarzyna Ślepokura: 0000-0001-8330-4218

Annie K. Powell: 0000-0003-3944-7427

Jerzy Lisowski: 0000-0002-4793-1748

\section{Present Address}

"A.M.: Solid State and Structural Chemistry Unit, Indian Institute of Science, C. V. Raman Road, Bangalore 560012, India.

\section{Notes}

The authors declare no competing financial interest.

\section{ACKNOWLEDGMENTS}

This research was supported by NCN (Narodowe Centrum Nauki, Poland) Grant 2015/19/B/ST5/00344. A.M. and A.K.P. are grateful to the $\mathrm{BMBF}$ "Pepschalter" project for financial support.

\section{REFERENCES}

(1) (a) Lindoy, L. F.; Park, K.-M.; Lee, S. S. Metals, macrocycles and molecular assemblies - macrocyclic complexes in metallo-supramolecular chemistry. Chem. Soc. Rev. 2013, 42, 1713-1727. (b) Vigato, P. A.; Tamburini, S.; Bertolo, L. The development of compartmental macrocyclic Schiff bases and related polyamine derivatives. Coord. Chem. Rev. 2007, 251, 1311-1492. (c) de Santana, R. C.; Fuentealba, P. A.; Maia, L. J. Q.; Paredes-Garcia, V.; Aravena, D.; Venegas-Yazigi, D.; Manzur, J.; Spodine, E. Solid state photoluminescence studies of $\left[\mathrm{EuL}^{\mathrm{n}} \mathrm{H}_{2}\left(\mathrm{NO}_{3}\right)_{3}\right]\left(\mathrm{H}_{2} \mathrm{O}\right)_{\mathrm{x}}$ macrocyclic complexes with Schiff base ligands. J. Lumin. 2018, 203, 7-15. (d) Polovkova, M. A.; Martynov, A. G.; Birin, K. P.; Nefedov, S. E.; Gorbunova, Y. G.; Tsivadze, A. Y. Determination of the Structural Parameters of Heteronuclear (Phthalocyaninato)bis(crownphthalocyaninato)lanthanide(III) Triple-Deckers in Solution by Simultaneous Analysis of NMR and Single-Crystal X-ray Data. Inorg. Chem. 2016, 55, 9258-9269. (e) Gao, F.; Feng, X.; Yang, L.; Chen, X. New sandwich-type lanthanide complexes based on closedmacrocyclic Schiff base and phthalocyanine molecules. Dalton Trans. 2016, 45, 7476-7482. (f) Chang, F.-F.; Zhang, L.; Zhao, P.-C.; Huang, W. Transmetalation for Flexible Pendant-Armed Schiff-Base Macrocyclic Complexes Influenced by Halide Effects. Inorg. Chem. 2018, 57, 1438-1448. (g) Antal, P.; Drahoš, B.; Herchel, R.; Trávnícek, Z. Structure and Magnetism of Seven-Coordinate Fe(III), $\mathrm{Fe}(\mathrm{II}), \mathrm{Co}(\mathrm{II})$ and $\mathrm{Ni}(\mathrm{II})$ Complexes Containing a Heptadentate 15Membered Pyridine-Based Macrocyclic Ligand. Eur. J. Inorg. Chem. 2018, 2018, 4286-4297. (h) Malthus, S. J.; Wilson, R. K.; Vikas
Aggarwal, A.; Cameron, S. A.; Larsen, D. S.; Brooker, S. Carbazolebased $\mathrm{N}_{4}$-donor Schiff base macrocycles: obtained metal free and as $\mathrm{Cu}(\mathrm{II})$ and $\mathrm{Ni}(\mathrm{II})$ complexes. Dalton Trans. 2017, 46, 3141-3149.

(2) (a) Kobyłka, M. J.; Janczak, J.; Lis, T.; Kowalik-Jankowska, T.; Kłak, J.; Pietruszka, M.; Lisowski, J. Trinuclear Cu(II) complexes of a chiral N6O3 amine. Dalton Trans. 2012, 41, 1503-1511. (b) Gao, J.; Zingaro, R. A.; Reibenspies, J. H.; Martell, A. E. Direct observation of enantioselective synergism at trimetallic centers. Org. Lett. 2004, 6, 2453-2455. (c) Korupoju, S. R.; Mangayarkarasi, N.; Zacharias, P. S.; Mizuthani, J.; Nishihara, H. Synthesis, structure, and DNA cleavage activity of new trinuclear $\mathrm{Zn}(3)$ and $\mathrm{Zn}(2) \mathrm{Cu}$ complexes of a chiral macrocycle: structural correlation with the active center of P1 nuclease. Inorg. Chem. 2002, 41, 4099-4101. (d) Cheng, L.; Wang, J.; Zhang, X.-Y.; Gou, S.-H.; Fang, L. A trinuclear copper (II) complex derived from a chiral $[3+3]$ phenol-based macrocycle: Synthesis, structure and magnetic properties. Inorg. Chem. Commun. 2014, 47, 144-147. (e) Gao, J.; Reibenspies, J. H.; Zingaro, R. A.; Woolley, F. R.; Martell, A. E.; Clearfield, A. Novel Chiral "Calixsalen" Macrocycle and Chiral Robson-type Macrocyclic Complexes. Inorg. Chem. 2005, 44, 232-241.

(3) (a) Löffler, M.; Gregoliński, J.; Korabik, M.; Lis, T.; Lisowski, J. Multinuclear $\mathrm{Ni}(\mathrm{II}), \mathrm{Cu}(\mathrm{II})$ and $\mathrm{Zn}(\mathrm{II})$ complexes of chiral macrocyclic nonaazamine. Dalton Trans. 2016, 45, 15586-15594. (b) González-Alvarez, A.; Alfonso, I.; Cano, J.; Díaz, P.; Gotor, V.; Gotor-Fernández, V.; García-España, E.; Garcia-Granda, S.; Jiménez, H. R.; Lloret, G. A Ferromagnetic $\left[\mathrm{Cu}_{3}(\mathrm{OH})_{2}\right]^{4+}$ Cluster Formed inside a Tritopic Nonaazapyridinophane: Crystal Structure and Solution Studies. Angew. Chem., Int. Ed. 2009, 48, 6055-6058.

(4) (a) Janczak, J.; Prochowicz, D.; Lewiński, J.; Fairen-Jimenez, D.; Bereta, T.; Lisowski, J. Trinuclear Cage-Like $\mathrm{Zn}^{\text {II }}$ Macrocyclic Complexes: Enantiomeric Recognition and Gas Adsorption Properties. Chem. - Eur. J. 2016, 22, 598-609. (b) Sarnicka, A.; Starynowicz, P.; Lisowski, J. Controlling the macrocycle size by the stoichiometry of the applied template ion. Chem. Commun. 2012, 48, 2237-2239.

(5) (a) Kobyłka, M. J.; Ślepokura, K.; Acebrón Rodicio, M.; Paluch, M.; Lisowski, J. Incorporation of Trinuclear Lanthanide(III) Hydroxo Bridged Clusters in Macrocyclic Frameworks. Inorg. Chem. 2013, 52, 12893-12903. (b) Paluch, M.; Ślepokura, K.; Lis, T.; Lisowski, J. Enantiopure trinuclear lanthanide(III) complexes: Cooperative formation of $\operatorname{Ln}_{3}\left(\mu_{3}-\mathrm{OH}\right)_{2}$ core within the macrocycle. Inorg. Chem. Commun. 2011, 14, 92-95.

(6) (a) Lin, S.-Y.; Guo, Y.-N.; Guo, Y.; Zhao, L.; Zhang, P.; Ke, H.; Tang, J. Macrocyclic ligand encapsulating dysprosium triangles: axial ligands perturbed magnetic dynamics. Chem. Commun. 2012, 48, 6924-6926. (b) Lin, S.-Y.; Wang, C.; Zhao, L.; Tang, J. Enantioselective Self-Assembly of Triangular Dy3 Clusters with Single Molecule Magnet Behavior. Chem. - Asian J. 2014, 9, 35583564.

(7) Paluch, M.; Lisowski, J.; Lis, T. Lanthanide complexes of chiral 3 +3 macrocycles derived from (1R,2R)-1,2-diaminocyclohexane and 2,6-diformyl-4-methylphenol. Dalton Trans. 2006, 381-388.

(8) Lin, S.-Y.; Wang, C.; Zhao, L.; Wu, J.; Tang, J. Chiral mononuclear lanthanide complexes and the field-induced single-ion magnet behaviour of a Dy analogue. Dalton Trans. 2015, 44, 223229.

(9) (a) Dhers, S.; Feltham, H. L. C.; Rouzieres, M.; Clerac, R.; Brooker, S. Macrocyclic \{3d-4f\} SMMs as building blocks for 1Dpolymers: selective bridging of $4 \mathrm{f}$ ions by use of an $\mathrm{O}$-donor ligand. Dalton Trans. 2016, 45, 18089-18093. (b) Feltham, H. L. C.; Dhers, S.; Rouzieres, M.; Clerac, R.; Powell, A. K.; Brooker, S. A family of fourteen soluble stable macrocyclic $\left[\mathrm{Ni}_{3}{ }^{\mathrm{II}} \mathrm{Ln}^{\mathrm{III}}\right]$ heterometallic $3 \mathrm{~d}-4 \mathrm{f}$ complexes. Inorg. Chem. Front. 2015, 2, 982-990. (c) Feltham, H. L. C.; Dumas, C.; Mannini, M.; Otero, E.; Sainctavit, P.; Sessoli, R.; Meledandri, C. J.; Brooker, S. Proof of Principle: Immobilisation of Robust $\mathrm{Cu}_{3}{ }_{3} \mathrm{~Tb}^{\mathrm{III}}$ Macrocycles on Small, Suitably Pre-functionalised Gold Nanoparticles. Chem. - Eur. J. 2017, 23, 2517-2521. (d) Feltham, H. L. C.; Lan, Y. H.; Klower, F.; Ungur, L.; Chibotaru, L. F.; Powell, A. K.; Brooker, S. A Non-sandwiched Macrocyclic Monolanthanide Single-Molecule Magnet: The Key Role 
of Axiality. Chem. - Eur. J. 2011, 17, 4362-4365. (e) Yamashita, A.; Watanabe, A.; Akine, S.; Nabeshima, T.; Nakano, M.; Yamamura, T.; Kajiwara, T. Wheel-Shaped $\mathrm{Er}^{\mathrm{III}} \mathrm{Zn}^{\mathrm{II}}{ }_{3}$ Single-Molecule Magnet: A Macrocyclic Approach to Designing Magnetic Anisotropy. Angew. Chem., Int. Ed. 2011, 50, 4016-4019.

(10) (a) Train, C.; Gruselle, M.; Verdaguer, M. The fruitful introduction of chirality and control of absolute configurations in molecular magnets. Chem. Soc. Rev. 2011, 40, 3297-3312. (b) Train, C.; Gheorghe, R.; Krstic, V.; Chamoreau, L.-M.; Ovanesyan, M. S.; Rikken, G. L. J. A.; Gruselle, M.; Verdaguer, M. Strong magneto-chiral dichroism in enantiopure chiral ferromagnets. Nat. Mater. 2008, 7, 729-734.

(11) (a) Chin, W.; Lin, P.-H. Influence of Energy Barriers in Triangular Dysprosium Single-Molecule Magnets through Different Substitutions on a Nitrophenolate-Type Coligand. Inorg. Chem. 2018, 57, 12448-12451. (b) Gysler, M.; El Hallak, F.; Ungur, L.; Marx, R.; Hakl, M.; Neugebauer, P.; Rechkemmer, Y.; Lan, Y. H.; Sheikin, I.; Orlita, M.; Anson, C. E.; Powell, A. K.; Sessoli, R.; Chibotaru, L. F.; van Slageren, J. Multitechnique investigation of $\mathrm{Dy}_{3}$-implications for coupled lanthanide clusters. Chem. Sci. 2016, 7, 4347-4354. (c) Zhang, L.; Zhang, P.; Zhao, L.; Wu, J. F.; Guo, M.; Tang, J. Single-molecule magnet behavior in an octanuclear dysprosium(III) aggregate inherited from helical triangular $\mathrm{Dy}_{3} \mathrm{SMM}$-building blocks. Dalton Trans. 2016, 45, 10556-10562. (d) Li, X.-L.; Wu, J.; Tang, J.; Le Guennic, B.; Shi, W.; Cheng, P. A planar triangular $\mathrm{Dy}_{3}+\mathrm{Dy}_{3}$ single-molecule magnet with a toroidal magnetic moment. Chem. Commun. 2016, 52, 9570-9573. (e) Lin, S.-Y.; Wernsdorfer, W.; Ungur, L.; Powell, A. K.; Guo, Y.-N.; Tang, J. K.; Zhao, L.; Chibotaru, L. F.; Zhang, H. J. Coupling Dy 33 Triangles to Maximize the Toroidal Moment. Angew. Chem., Int. Ed. 2012, 51, 12767-12771. (f) Lin, S.Y.; Zhao, L.; Guo, Y.-N.; Zhang, P.; Guo, Y.; Tang, J. Two New Dy-3 Triangles with Trinuclear Circular Helicates and Their SingleMolecule Magnet Behavior. Inorg. Chem. 2012, 51, 10522-10528. (g) Xue, S.; Chen, X.-H.; Zhao, L.; Guo, Y.-N.; Tang, J. Two BulkyDecorated Triangular Dysprosium Aggregates Conserving VortexSpin Structure. Inorg. Chem. 2012, 51, 13264-13270. (h) Hewitt, I. J.; Tang, J.; Madhu, N. T.; Anson, C. E.; Lan, Y.; Luzon, J.; Etienne, M.; Sessoli, R.; Powell, A. K. Coupling Dy-3 Triangles Enhances Their Slow Magnetic Relaxation. Angew. Chem., Int. Ed. 2010, 49, 63526356. (i) Sessoli, R.; Powell, A. K. Strategies towards single molecule magnets based on lanthanide ions. Coord. Chem. Rev. 2009, 253, 2328-2341. (j) Andrews, P. C.; Deacon, G. B.; Frank, R.; Fraser, B. H.; Junk, P. C.; MacLellan, J. G.; Massi, M.; Moubaraki, B.; Murray, K. S.; Silberstein, M. Formation of Ho ${ }^{\text {III }}$ Trinuclear Clusters and Gd ${ }^{I I I}$ Monodimensional Polymers Induced by ortho and para Regioisomers of Pyridyl-Functionalised beta-Diketones: Synthesis, Structure, and Magnetic Properties. Eur. J. Inorg. Chem. 2009, 2009, 744-751. (k) Chibotaru, L. F.; Ungur, L.; Soncini, A. The origin of nonmagnetic Kramers doublets in the ground state of dysprosium triangles: evidence for a toroidal magnetic moment. Angew. Chem., Int. Ed. 2008, 47, 4126-4129. (1) Luzon, J.; Bernot, K.; Hewitt, I. J.; Anson, C. E.; Powell, A. K.; Sessoli, R. Spin chirality in a molecular dysprosium triangle: The archetype of the noncollinear ising model. Phys. Rev. Lett. 2008, 100, 247205. (m) Tang, J.; Hewitt, I.; Madhu, N. T.; Chastanet, G.; Wernsdorfer, W.; Anson, C. E.; Benelli, C.; Sessoli, R.; Powell, A. K. Dysprosium triangles showing singlemolecule magnet behavior of thermally excited spin states. Angew. Chem., Int. Ed. 2006, 45, 1729-1733. (n) Hussain, B.; Savard, D.; Burchell, T. J.; Wernsdorfer, W.; Murugesu, M. Linking high anisotropy $\mathrm{Dy}_{3}$ triangles to create a $\mathrm{Dy}_{6}$ single-molecule magnet. Chem. Commun. 2009, 9, 1100-1102. (o) Burrow, C. E.; Burchell, T. J.; Lin, P.-H.; Habib, F.; Wernsdorfer, W.; Clerac, R.; Murugesu, M. Salen-Based $\left[\mathrm{Zn}_{2} \mathrm{Ln}_{3}\right]$ Complexes with Fluorescence and SingleMolecule-Magnet Properties. Inorg. Chem. 2009, 48, 8051-8053. (p) Li, X.-L.; Li, H.; Chen, D.-M.; Wang, C.; Wu, J.; Tang, J.; Shi, W.; Cheng, P. Planar $\mathrm{Dy}_{3}+\mathrm{Dy}_{3}$ clusters: design, structure and axial ligand perturbed magnetic dynamics. Dalton Trans. 2015, 44, 20316-20320.

(12) (a) Novitchi, G.; Pilet, G.; Ungur, L.; Moshchalkov, V. V.; Wernsdorfer, W.; Chibotaru, L. F.; Luneau, D.; Powell, A. K.
Heterometallic $\mathrm{Cu}^{\mathrm{II}} / \mathrm{Dy}{ }^{\mathrm{III}} 1 \mathrm{D}$ chiral polymers: chirogenesis and exchange coupling of toroidal moments in trinuclear $\mathrm{Dy}_{3}$ single molecule magnets. Chem. Sci. 2012, 3, 1169-1176. (b) Peng, J.-B.; Zhang, Q.-C.; Kong, X.-J.; Zheng, Y.-Z.; Ren, Y.-P.; Long, L.-S.; Huang, R.-B.; Zheng, L.-S.; Zheng, Z. High-Nuclearity 3d-4f Clusters as Enhanced Magnetic Coolers and Molecular Magnets. J. Am. Chem. Soc. 2012, 134, 3314-3317. (c) Novitchi, G.; Wernsdorfer, W.; Chibotaru, L. F.; Costes, J.-P.; Anson, C. E.; Powell, A. K. Supramolecular "double-propeller" dimers of hexanuclear $\mathrm{Cu}^{\mathrm{II}} / \mathrm{Ln}^{\mathrm{III}}$ complexes: a $\left\{\mathrm{Cu}_{3} \mathrm{Dy}_{3}\right\}^{2}$ single-molecule magnet. Angew. Chem., Int. Ed. 2009, 48, 1614-1619. (d) Aronica, C.; Pilet, G.; Chastanet, G.; Wernsdorfer, W.; Jacquot, J.-F.; Luneau, D. A Nonanuclear Dysprosium(III)-Copper(II) Complex Exhibiting Single-Molecule Magnet Behavior with Very Slow Zero-Field Relaxation. Angew. Chem., Int. Ed. 2006, 45, 4659-4662. (e) Vignesh, K. R.; Soncini, A.; Langley, S. K.; Wernsdorfer, W.; Murray, K. S.; Rajaraman, G. Ferrotoroidic ground state in a heterometallic $\left\{\mathrm{Cr}^{\mathrm{III}} \mathrm{Dy}{ }_{6}^{\mathrm{II}}\right\}$ complex displaying slow magnetic relaxation. Nat. Commun. 2017, 8, 1023. (f) Vignesh, K. R.; Langley, S. K.; Swain, A.; Moubaraki, B.; Damjanovic, M.; Wernsdorfer, W.; Rajaraman, G.; Murray, K. S. Slow Magnetic Relaxation and Single-Molecule Toroidal Behaviour in a Family of Heptanuclear $\left\{\mathrm{Cr}^{\mathrm{III}} \mathrm{Ln}_{6}^{\mathrm{III}}{ }_{6}\right\}(\mathrm{Ln}=\mathrm{Tb}, \mathrm{Ho}, \mathrm{Er})$ Complexes. Angew. Chem., Int. Ed. 2018, 57, 779-784.

(13) Selected examples of hexanuclear dysprosium(III) complexes: (a) Calvez, G.; Le Natur, F.; Daiguebonne, C.; Bernot, K.; Suffren, Y.; Guillou, O. Lanthanide-based hexa-nuclear complexes and their use as molecular precursors. Coord. Chem. Rev. 2017, 340, 134-153. (b) Costes, J. P.; Duhayon, C. An Ionic Dysprosium Complex Made of a Hexanuclear Dy 6 Cationic Cluster and a Mononuclear Dy Anionic Unit. Eur. J. Inorg. Chem. 2014, 2014, 4745-4749. (c) Holmberg, R. J.; Kuo, C. J.; Gabidullin, B.; Wang, C. W.; Clerac, R.; Murugesu, M.; Lin, P. H. A propeller-shaped $\mu_{4}$-carbonate hexanuclear dysprosium complex with a high energetic barrier to magnetisation relaxation. Dalton Trans. 2016, 45, 16769-16773. (d) Holynska, M.; Clérac, R.; Rouzieres, M. Lanthanide Complexes with Multidentate Oxime Ligands as Single-Molecule Magnets and Atmospheric Carbon Dioxide Fixation Systems. Chem. - Eur. J. 2015, 21, 13321-13329. (e) Liu, Z. Y.; Zou, H. H.; Wang, R.; Chen, M. S.; Liang, F. P. Structure and magnetism of two chair-shaped hexanuclear dysprosium(III) complexes exhibiting slow magnetic relaxation. RSC Adv. 2018, 8, 767-774. (f) Tian, H. Q.; Guo, Y. N.; Zhao, L.; Tang, J. K.; Liu, Z. L. Hexanuclear Dysprosium(III) Compound Incorporating Vertex- and Edge-Sharing $\mathrm{Dy}_{3}$ Triangles Exhibiting Single-MoleculeMagnet Behavior. Inorg. Chem. 2011, 50, 8688-8690. (g) Tian, H. Q.; Wang, M.; Zhao, L.; Guo, Y. N.; Guo, Y.; Tang, J. K.; Liu, Z. L. A Discrete Dysprosium Trigonal Prism Showing Single-Molecule Magnet Behaviour. Chem. - Eur. J. 2012, 18, 442-445. (h) Ungur, L.; Langley, S. K.; Hooper, T. N.; Moubaraki, B.; Brechin, E. K.; Murray, K. S.; Chibotaru, L. F. Net Toroidal Magnetic Moment in the Ground State of a $\{$ Dy-6\}-Triethanolamine Ring. J. Am. Chem. Soc. 2012, 134, 18554-18557. (i) Baniodeh, A.; Magnani, N.; Bräse, S.; Anson, C. E.; Powell, A. K. Ligand field variations: tuning the toroidal moment of Dy 6 rings. Dalton Trans. 2015, 44, 6343-6347.

(14) Llunell, M.; Casanova, D.; Cirera, J.; Alemany, P.; Alvarez, S. SHAPE: Program for the Stereochemical Analysis of Molecular Fragments by Means of Continuous Shape Measures and Associated Tools, version 2.1; Universitat de Barcelona: Barcelona, 2013.

(15) (a) Guo, Y.-N.; Xu, G.-F.; Gamez, P.; Zhao, L.; Lin, S.-Y.; Deng, R.; Tang, J.; Zhang, H.-J. Two-Step Relaxation in a Linear Tetranuclear Dysprosium(III) Aggregate Showing Single-Molecule Magnet Behavior. J. Am. Chem. Soc. 2010, 132, 8538-8539. (b) Lin, S.-Y.; Zhao, L.; Ke, H.; Guo, Y.-N.; Tang, J.; Guo, Y.; Dou, J. Steric hindrances create a discrete linear $\mathrm{Dy}_{4}$ complex exhibiting SMM behavior. Dalton Trans. 2012, 41, 3248-3252. (c) Ke, H.; Xu, G.-F.; Guo, Y.-N.; Gamez, P.; Beavers, C. M.; Teat, S. J.; Tang, J. A linear tetranuclear dysprosium(III) compound showing single-molecule magnet behavior. Chem. Commun. 2010, 46, 6057-6059. (d) Yadav, M.; Mondal, A.; Mereacre, V.; Jana, S. K.; Powell, A. K.; Roesky, P. W. Tetranuclear and Pentanuclear Compounds of the 
Rare-Earth Metals: Synthesis and Magnetism. Inorg. Chem. 2015, 54, $7846-7856$.

(16) Long, J.; Habib, F.; Lin, P.-H.; Korobkov, I.; Enright, G.; Ungur, L.; Wernsdorfer, W.; Chibotaru, L. F.; Murugesu, M. SingleMolecule Magnet Behavior for an Antiferromagnetically Superexchange-Coupled Dinuclear Dysprosium(III) Complex. J. Am. Chem. Soc. 2011, 133, 5319-5328.

(17) (a) Chandrasekhar, V.; Hossain, S.; Das, S.; Biswas, S.; Sutter, J.-P. Rhombus-Shaped Tetranuclear $\left[\mathrm{Ln}_{4}\right]$ Complexes $[\mathrm{Ln}=\mathrm{Dy}(\mathrm{III})$ and $\mathrm{Ho}(\mathrm{III})]$ : Synthesis, Structure, and SMM Behavior. Inorg. Chem. 2013, 52, 6346-6353. (b) Bi, Y.; Wang, X.-T.; Liao, W.; Wang, X.; Deng, R.; Zhang, H.; Gao, S. Thiacalix[4] arene-Supported Planar $\mathrm{Ln}_{4}$ $\left(\mathrm{Ln}=\mathrm{Tb}^{\mathrm{III}}, \mathrm{Dy}{ }^{\mathrm{III}}\right)$ Clusters: Toward Luminescent and Magnetic Bifunctional Materials. Inorg. Chem. 2009, 48, 11743-11747. (c) Xue, S.; Zhao, L.; Guo, Y.-N.; Chen, X.-H.; Tang, J. Field enhanced thermally activated mechanism in a square $\mathrm{Dy}_{4}$ aggregate. Chem. Commun. 2012, 48, 7031-7033.

(18) (a) Cole, K. S.; Cole, R. H. Dispersion and Absorption in Dielectrics I. Alternating Current Characteristics. J. Chem. Phys. 1941, 9, 341-351. (b.) Dekker, C.; Arts, A. F. M.; de Wijn, H. W.; van Duyneveldt, A. J.; Mydosh, J. A. Activated dynamics in a twodimensional Ising spin glass: $\mathrm{Rb}_{2} \mathrm{Cu}_{1-\mathrm{x}} \mathrm{Co}_{\mathrm{x}} \mathrm{F}_{4}$. Phys. Rev. B: Condens. Matter Mater. Phys. 1989, 40, 11243-11251.

(19) (a) Guo, Y.-N.; Xu, G.-F.; Guo, Y.; Tang, J. Relaxation dynamics of dysprosium(III) single molecule magnets. Dalton Trans. 2011, 40, 9953-9963. (b) http://www.nfchilton.com/cc-fit.html.

(20) (a) Abragam, A.; Bleaney, B. In Electron paramagnetic resonance of transition ions; Oxford University Press, 1970. (b) Carlin, R. L.; van Duyneveldt, A. J. In Magnetic properties of transition metal compounds; Springer-Verlag, 1977.

(21) (a) CryAlis PRO in Xcalibur software; Agilent Technologies: Yarnton, England, 2012. (b) CrysAlis CCDCrysAlis RED in KM-4 CCD software; Oxford Diffraction: Wroclaw, Poland, 2004.

(22) Sheldrick, G. M. A short history of SHELX. Acta Crystallogr., Sect. A: Found. Crystallogr. 2008, A64, 112-122.

(23) Sheldrick, G. M. Crystal structure refinement with SHELXL. Acta Crystallogr., Sect. C: Struct. Chem. 2015, C71, 3-8.

(24) MERCURY, Program for Crystal Structure Visualisation and Exploration, version 3.8; CCDC Cambridge University, 2016. 